\title{
Hospital Preparedness Assessment against COVID-19 Pandemic: A Case Study in Turkish Tertiary Healthcare Services
}

\author{
Muhammet Gul $\mathbb{D}^{1}$ and Melih Yucesan $\mathbb{D}^{2}$ \\ ${ }^{1}$ Munzur University, Department of Emergency Aid and Disaster Management, Tunceli 62000, Turkey \\ ${ }^{2}$ Munzur University, Department of Mechanical Engineering, Tunceli 62000, Turkey \\ Correspondence should be addressed to Melih Yucesan; melihyucesan@munzur.edu.tr
}

Received 13 July 2020; Revised 1 December 2020; Accepted 17 December 2020; Published 8 January 2021

Academic Editor: Dylan F. Jones

Copyright ( $) 2021$ Muhammet Gul and Melih Yucesan. This is an open access article distributed under the Creative Commons Attribution License, which permits unrestricted use, distribution, and reproduction in any medium, provided the original work is properly cited.

\begin{abstract}
Hospitals play a critical role in providing essential health services to people in the healthcare system. Healthcare systems around the world have faced some issues in responding to patients with various disease severity levels. Nowadays, the world as a whole is combating a pandemic called COVID-19. This pandemic causes an increase in the disease spread with fluctuated patient demand that may affect the hospitals' capacity and overall functioning and risks rising based on hospital site, medical staff, patient, and healthcare process. To deal with the challenges of the COVID-19 pandemic, hospitals must have completed their preparations before these events occur. Therefore, this study proposes an integrated approach based on the decision-making concept with interval-valued spherical fuzzy sets (IVSFSs) to the hospital preparedness assessment problem. A technique for order preference by similarity to ideal solution (TOPSIS) extended with IVSFSs is used to rank hospitals from Turkish tertiary healthcare services. A checklist reported by the World Health Organization (WHO) is adapted to conform to Turkey's COVID-19 pandemic management. Ninety-nine subcomponents of the adapted checklist under ten components are weighted by interval-valued spherical weighted arithmetic mean (IVSWAM) operator. The hospitals in the problem are then ranked concerning these weighted subcomponents. With the proposed approach, a COVID-19 pandemic preparedness index is determined for the observed hospitals. In addition, a separate index based on each main component (component-based ranking) is determined. These indexes are vital indicators in determining in which aspects hospitals are ready and in what aspects hospitals are not prepared for pandemics. The proposed approach can be adaptable and applied by national policymakers in assessing all hospitals of the country against the COVID-19 pandemic.
\end{abstract}

\section{Introduction}

Hospitals play a critical role in providing primary health care to people, especially in natural or human-made disasters. Pandemics can lead to an increasing spread of disease, with irregular and suddenly increasing patient demands that can affect hospitals' capacity and the overall functioning of the health system. To cope with the difficulty of such an epidemic disaster, hospitals must have completed their preparations before these events occur. Nowadays, an overwhelming majority of the world is fighting against an epidemic called COVID-19. The world faces the demand for infected patients who arrive at the hospitals heavily and irregularly.
COVID-19, a new type of coronavirus, is an infectious disease that first appeared on December 30, 2019, in Wuhan, China [1]. The World Health Organization (WHO) declared COVID-19 later as an epidemic. In the period of nearly four months, the infection, which first expanded with Iran and Italy, is spread worldwide. As of April 22, 2020, it has caused nearly 2.5 million cases and 169,000 deaths in the world [2]. The symptoms of COVID-19 are not specific, and they can range from no symptoms (asymptomatic) to severe pneumonia and death. According to the figures of the report "Report of the WHO-China Joint Mission on Coronavirus Disease 2019 (COVID-19)," typical signs and symptoms are expressed such as fever, dry cough, fatigue, sputum production, shortness of breath, sore throat, and headache [3]. 
As of April 22, 2020, similar to countries' fights against this pandemic throughout the world, Turkey continues its struggle. The mortality rate, the number of intensive care patients, and the number of intubated patients are better than the most developed countries in the world. The mortality rate was $2.4 \%$ as of April 22 [4]. Also, the total number of infected cases to the total number of cases examined is around $13 \%$. Turkey is among the top six countries in the world in terms of the total number of tests and has reached this level quickly. All these statistical indicators show that Turkey is at a better level than the world average because of Turkey's early isolation decisions and the case of being prepared for such an event. Therefore, hospitals are required to be ready for such pandemics.

For Europe, the World Health Organization Regional Office has published a checklist entitled "Hospital Readiness Checklist for COVID-19" to take in the context of a continuous hospital emergency preparedness process [5]. In this document, they have advised hospitals to manage the preparatory process under ten critical components as follows: surge capacity, infection prevention and control, case management, human resources, continuity of essential health services and patient care, surveillance: early warning and monitoring, communication, logistics and supply chain management including pharmaceuticals, laboratory services, and vital support services. Hospitals are facilities with complex processes, mostly connected to external support and supply lines [6]. Even in regular times, many hospitals operate at full capacity or close to maximum capacity. In epidemic conditions, with surge demand, hospitals may find it challenging to carry out their necessary functional activities, and capacity may no longer meet this demand [7]. Even a well-prepared hospital for disasters will have a hard time coping with the consequences of a COVID-19 pandemic. It is an effective hospital management policy that will reduce these difficulties to some extent. In this checklist report, it is highlighted that this effective hospital management will help (1) continuity of essential services, (2) well-coordinated implementation of priority action, (3) clear and accurate internal and external communication, (4) swift adaptation to increased demands, (5) effective use of scarce resources, and (6) safe environment for health workers [5].

Based on the World Health Organization's checklist report, this study aims to develop a ranking model for hospitals regarding their preparation for the COVID-19 pandemic. In this context, components and subcomponents in the checklist are adapted to conform to Turkey's pandemic management. The model consists of many components and has a multicriteria decision-making structure in the final decision expressed as "goal-alternative-criterion and subcriterion-performance rating of each alternative with respect to the criteria." Therefore, in this study, a "multicriteria decision-making (MCDM)" based model was used to evaluate hospitals' level of preparedness against the COVID19 pandemic. The model is based on the technique for order preference by similarity to ideal solution (TOPSIS) concept. It was first developed by Yoon and Hwang [8]. It represents the MCDM problem, aiming to find the best alternative considering the distances from the positive and the negative ideal solutions. In the scientific literature, several TOPSIS versions are suggested for selection, ranking, and sorting problems [9-15].

Since we do not have precise data for the evaluation of these components and their related subcomponents, linguistic expressions and corresponding fuzzy numbers were used in the evaluation. Fuzzy logic is a concept proposed by Zadeh to eliminate the disadvantages of classical 0-1 logic. Several extensions have been developed in the first version. In this study, spherical fuzzy sets, which are proposed by Kutlu Gündoğdu and Kahraman [16] for the first time in the literature, are used together with the TOPSIS MCDM method. Kutlu Gündoğdu and Kahraman [16] proposed spherical fuzzy sets, which reflect uncertainty and ambiguity in real-world decision problems better than classical fuzzy set theory. They are mathematically based on a membership function on a spherical surface. They independently describe the degree of membership, nonmembership, and hesitancy in a larger domain (the sum of these three values must be between 0 and 1). They are considered as the integration of Pythagorean fuzzy sets and neutrosophic sets. They eliminate some aspects of neutrosophic sets and Pythagorean fuzzy sets as follows [16-18]: they cannot permit the sum of membership, nonmembership, and hesitancy degrees to be larger than one, and they do not disregard an independent hesitancy, unlike Pythagorean fuzzy sets.

In the existing study, a particular branch of spherical sets, "interval-valued spherical fuzzy sets (IVSFSs)," is used with TOPSIS. Interval-valued fuzzy sets provide decision makers to model their decision-making problem via a fuzzy interval framework instead of a single point. By this aspect, it helps decision makers to clarify their judgments more accurately. Initially, TOPSIS is merged with IVSFSs to evaluate hospital preparedness levels against the COVID-19 pandemic. The experienced hospital directors perform linguistic evaluations of hospitals with respect to the adapted components. Then, a final score is determined for each assessed hospital. The proposed model is tested on three Turkish hospitals that provide health care under the tertiary step. With the obtained results from the application of this proposed approach, a pandemic preparedness index is determined for the observed hospitals. In addition, it is considered to make a ranking and calculate the index based on each main component (component-based ranking). These indexes are vital indicators in determining in which aspects hospitals are ready and in what aspects hospitals are not prepared for pandemics.

\section{Literature Review}

The topic of hospital readiness evaluation against disasters is studied very limitedly in the literature. Scholars deal with this topic either as an MCDM structure or a conceptual/questionnaire-based structure. Nekoie-Moghadam et al. [19] presented a systematic literature review of tools/checklists used for the evaluation of hospital disaster evaluation. They mentioned some relevant themes such as logistics, planning, human resources, triage, communication, command and control, structural and nonstructural preparedness, training, 
evacuation, recovery after a disaster, coordination, transportation, surge capacity, and safety [19-21]. Fifteen studies are included in the scope of this review. However, none of them concern with the MCDM concept. Some of the reviewed ones are reports suggested by the WHO as we adapted in this study and guidelines [19]. Most of them are based on a questionnaire-based assessment tool [22-27]. Apart from this type of disaster preparedness evaluation studies, there are MCDM-based papers in the literature. For example, Hosseini et al. [28] developed a hospital ranking model based on disaster preparedness using the TOPSIS multicriteria method. They used four dimensions and twentyone indicators under these dimensions, as in the study of Mulyasari et al. [25], to assess hospitals. Eight hospitals in Iran were evaluated in terms of four dimensions. The results of their research showed that the structural and functional preparedness dimensions had the highest and lowest weights, respectively. However, in their study, no MCDM method is used to assign the importance of these dimensions. Instead, they were just determined via subjective judgment. MCDM was used in the ranking of hospitals. A second significant contribution is performed by Ortiz-Barrios et al. [29]. In that study, the disaster readiness of emergency departments is assessed with an analytical MCDM approach. The approach consists of the analytic hierarchy process (AHP), decisionmaking trial and evaluation laboratory (DEMATEL), and TOPSIS. Ortiz-Barrios et al.'s study [29] is different from Hosseini et al.'s study [28] in the following aspects: it applies a pairwise comparison between the dimensions and their subdimensions via AHP. They also determined interrelations between criteria via DEMATEL. Finally, the ranking of Colombian emergency departments in terms of disaster readiness is carried out via TOPSIS.

There are also cross-sectional studies using statistical methodologies, Delphi, and similar tools [30, 31]. For a broad literature review in disaster preparedness of hospitals, scholars can refer to the papers of Fallah-Aliabadi et al. [20], Verheul and Dückers [21], Alruwaili et al. [32], and NekoieMoghadam et al. [19]. Tabatabaei and Abbasi [33] performed a cross-sectional study in some Iranian hospitals to assess risks during disasters based on the hospital safety index. They designed questionnaires for hospitals' disaster ability with 145 metrics in structural, functional, and nonstructural factors. This study is not a fully numerical or MCDM-based study. Otherwise, it benefits from a semiquantitative disaster preparedness assessment method. Similarly, Naser et al. [34] made a cross-sectional study to assess hospital disaster preparedness in South Yemen. The results of the study showed that hospitals had not reached an unacceptable level of readiness. Samsuddin et al. [35] performed a cross-sectional study for disaster preparedness attributes and the hospital's resilience in Malaysia. The results showed that human resources and training and the ability to adapt in a timely manner are ranked as the most critical attribute. Marzaleh et al. [36] proposed an approach using Delphi for hospital emergency room preparedness against radiation and nuclear incidents in Iran. They mentioned 31 criteria under three main classes: staff, stuff, and structure (system). Results indicated that staff and stuff preparedness had the highest and lowest priority levels, respectively. Shabanikiya et al. [37] designed a Delphi-based tool for hospital preparedness for surge capacity during disasters and assessed 64 components in five categories and 13 subcategories.

In light of the studies mentioned above, many contributions are performed for hospital disaster preparedness. Most of the papers contribute to the literature by proposing the cross-sectional questionnaire-based frameworks that we discussed. On the other hand, conceptual-based models that suggest new attributes regarding hospital disaster readiness and review papers that provide a comprehensive overview of the topic are also widespread. Our brief reviews in this section show the importance of hospital disaster preparedness assessment from the viewpoint of MCDM through the literature. It can be observed that there exists a wide range of MCDM methods used in the literature applied to various areas. So far, however, there have been limited papers regarding the applications of such methods in hospital disaster preparedness. Moving from this point, we aim to develop an MCDM model supported with interval-valued spherical fuzzy set concept for hospital preparedness assessment against the COVID-19 pandemic.

We developed our model for a newly occurred pandemic that spreads over the world in a short time. We followed and adapted the checklist of the WHO for the COVID-19 pandemic. Our proposed model specifically deals with hospital disaster readiness assessment and hospital ranking. Our study is different from similar contributions in the literature in the following aspects:

(1) The suggested approach adapted the components and subcomponents of the WHO's checklist [5]. As this checklist is created considering all countries of the world's status, our model is based on a strong background. Our model is also adaptable for all countries and the other disasters except the COVID19 pandemic.

(2) We developed an MCDM-fuzzy integrated approach that includes TOPSIS and interval-valued spherical fuzzy sets. In determining hospital disaster preparedness's evaluation components/subcomponents, an interval-valued spherical weighted arithmetic mean (IVSWAM) operator is used. Then, in the hospital ranking phase, interval-valued spherical fuzzy TOPSIS is applied. Spherical fuzzy sets eliminate some missing aspects of neutrosophic sets and Pythagorean fuzzy sets by not permitting the sum of membership, nonmembership, and hesitancy degrees to be larger than one and not disregarding an independent hesitancy, unlike Pythagorean fuzzy sets. In view of the TOPSIS MCDM method's characteristics and spherical fuzzy set concept either individually or an integrated style, our approach can handle the problem systematically and analytically.

(3) Our approach is implemented in Turkish tertiary healthcare services. For implementation, three tertiary hospitals placed in the Eastern Black Sea Region of Turkey are selected. As an additional analysis, a secondary ranking of hospitals by major components 
was studied (10 components, as stated in the WHO's adapted checklist) and an overall ranking was obtained. This analysis can help hospital decision makers and national policymakers determine in which aspects hospitals are ready and in what aspects hospitals are not prepared for pandemics.

\section{Methodology}

3.1. Overview of Spherical and Interval-Valued Spherical Fuzzy Sets. Spherical fuzzy sets are the integration of Pythagorean fuzzy sets and neutrosophic sets. There are three membership degrees named membership, nonmembership, and hesitancy in intuitionistic and Pythagorean fuzzy sets. Membership functions in neutrosophic sets are defined under three pillars: truthiness, falsity, and indeterminacy membership. The sum of these three membership values can be between 0 and 3. In spherical fuzzy sets, while the squared sum of three parameters can be between 0 and 1 , each of them can be defined between 0 and 1 independently. For detailed information on this type of fuzzy sets, readers can refer to Kutlu Gundogdu and Kahraman [16] who are the authors and first-time developers of this type of fuzzy set.

Spherical fuzzy sets are applied in multicriteria problems [38-43] and combined with frequently used MCDM methods, although it has been recently emerged [44]. AHP [45], TOPSIS [16, 18, 46], VIKOR [47, 48], weighted aggregated sum product assessment (WASPAS) [49], quality function deployment (QFD) [50], MULTIMOORA [51], combinative distance-based assessment (CODAS) [52], and decision-making trial and evaluation laboratory (DEMATEL) [53] are MCDM methods extended with spherical fuzzy sets.

Unlike the previous TOPSIS studies extended with spherical fuzzy sets (mostly related to numerical examples to demonstrate the methodology), this study focuses on hospital readiness assessment against COVID-19. Although it has some application of hospital location analysis [46], 3D printer selection [16], and supplier selection [18], it has no application domain in public health, especially in the emerging COVID-19 pandemic. Thus, this work is the first of its kind in addressing (1) the use of IVSF-TOPSIS in the public health domain and (2) the application of compromise ranking MCDM under uncertainty in the management of COVID-19 pandemic as a global public health emergency. It also advances the evolving literature of COVID-19 by effectively adopting the comprehensive critical criteria for hospital readiness assessment, which may be set as guidelines for relevant policymakers and decision makers.

IVSFS is a special sub-branch of spherical fuzzy set, and an IVSFS $\widetilde{S}_{i}$ of the universe of discourse $U$ is defined as follows:

$$
\widetilde{S}_{i}=\left\{u,\left(\left[\mu \frac{L}{S_{S_{i}}}(u), \mu_{S_{i}}^{U}(u)\right],\left[v_{S_{i}}^{L}(u), v_{S_{i}}^{U}(u)\right],\left(\left[\pi \tilde{S}_{S_{i}}^{L}(u), \pi_{S_{i}}^{U}(u)\right]\right) \mid u \epsilon U\right\},\right.
$$

where

$$
\begin{aligned}
& 0 \leq \mu \stackrel{\sim}{L}(u) \leq \mu S_{S_{i}}^{U}(u) \leq 1, \\
& 0 \leq v \frac{L}{S_{i}}(u) \leq v \underset{S_{i}}{\frac{U}{u}}(u) \leq 1, \\
& 0 \leq \pi \underset{S_{i}}{L}(u) \leq \pi \underset{S_{i}}{\frac{U}{L}}(u) \leq 1 .
\end{aligned}
$$

Some mathematical operations with IVSFSs are defined in the following formulas benefiting from Kutlu Gundogdu and Kahraman [16].

Let $\widetilde{S}_{1}$ and $\widetilde{S}_{2}$ be two different interval-valued spherical fuzzy numbers of the universe of discourse $U$.

$$
\begin{aligned}
& \widetilde{S}_{1}=\left\{u,\left(\left[\mu \sim_{S_{1}}^{L}(u), \mu \underset{S_{1}}{U}(u)\right],\left[v \underset{S_{1}}{\stackrel{L}{L}}(u), v \underset{S_{1}}{\stackrel{U}{U}}(u)\right],\left(\left[\pi \pi_{S_{1}}^{L}(u), \pi \pi_{S_{1}}^{U}(u)\right]\right) \mid u \epsilon U\right\},\right. \\
& \widetilde{S}_{2}=\left\{u,\left(\left[\mu \mu_{S_{2}}^{L}(u), \mu \underset{S_{2}}{U}(u)\right],\left[v \underset{S_{2}}{\stackrel{L}{L}}(u), v \underset{S_{2}}{\stackrel{U}{U}}(u)\right],\left(\left[\pi \underset{S_{2}}{\stackrel{L}{L}}(u), \pi \pi_{S_{2}}^{U}(u)\right]\right) \mid u \epsilon U\right\} .\right.
\end{aligned}
$$


To avoid any complexity in the calculation, a leaner formulation is designed as follows: let $\widetilde{S}_{1}=\left[k_{1}, l_{1}\right]$, $\left[m_{1}, n_{1}\right],\left[p_{1}, r_{1}\right]$ and $\widetilde{S}_{2}=\left[k_{2}, l_{2}\right],\left[m_{2}, n_{2}\right],\left[p_{2}, r_{2}\right]$.

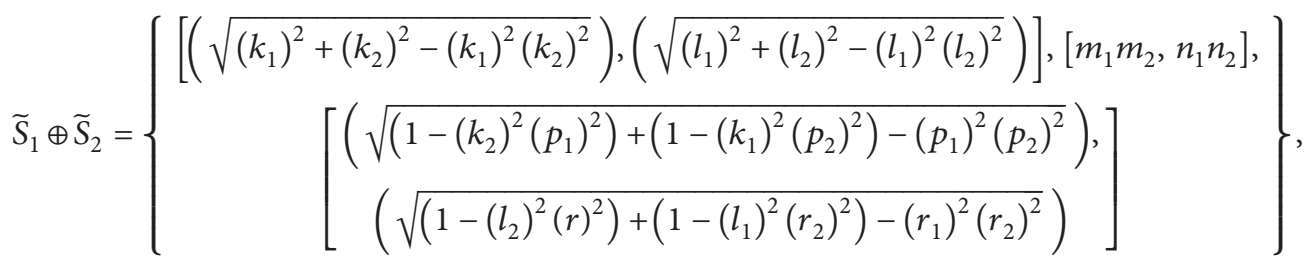

$$
\begin{aligned}
& \widetilde{S}_{1} \otimes \widetilde{S}_{2}=\left\{\left[k_{1} k_{2}, l_{1} l_{2}\right],\left[\left(\sqrt{\left(m_{1}\right)^{2}+\left(m_{2}\right)^{2}-\left(m_{1}\right)^{2}\left(m_{2}\right)^{2}}\right),\left(\sqrt{\left(n_{1}\right)^{2}+\left(n_{2}\right)^{2}-\left(n_{1}\right)^{2}\left(n_{2}\right)^{2}}\right)\right],\right. \\
& \left.\left[\begin{array}{c}
\left(\sqrt{\left(1-\left(m_{2}\right)^{2}\left(p_{1}\right)^{2}\right)+\left(1-\left(m_{1}\right)^{2}\left(p_{2}\right)^{2}\right)-\left(p_{1}\right)^{2}\left(p_{2}\right)^{2}}\right) \\
\left(\sqrt{\left(1-\left(n_{2}\right)^{2}(r)^{2}\right)+\left(1-\left(n_{1}\right)^{2}\left(r_{2}\right)^{2}\right)-\left(r_{1}\right)^{2}\left(r_{2}\right)^{2}}\right)
\end{array}\right]\right\} \\
& \lambda \widetilde{S}_{1}=\left\{\begin{array}{c}
{\left[\sqrt{\left(1-\left(1-\left(k_{1}\right)^{2}\right)^{\lambda}\right)}, \sqrt{\left(1-\left(1-\left(k_{1}\right)^{2}\right)^{\lambda}\right)}\right],\left[\left(m_{1}\right)^{\lambda},\left(n_{1}\right)^{\lambda}\right],} \\
{\left[\sqrt{\left(1-\left(k_{1}\right)^{2}\right)^{\lambda}-\left(1-\left(k_{1}\right)^{2}-\left(p_{1}\right)^{2}\right)^{\lambda}}, \sqrt{\left(1-\left(l_{1}\right)^{2}\right)^{\lambda}-\left(1-\left(l_{1}\right)^{2}-\left(r_{1}\right)^{2}\right)^{\lambda}}\right]}
\end{array},\right. \\
& \widetilde{S}_{1}^{\lambda}=\left\{\begin{array}{c}
{\left[\left(k_{1}\right)^{\lambda},\left(l_{1}\right)^{\lambda}\right],\left[\sqrt{\left(1-\left(1-\left(m_{1}\right)^{2}\right)^{\lambda}\right)}, \sqrt{\left(1-\left(1-\left(n_{1}\right)^{2}\right)^{\lambda}\right)}\right],} \\
{\left[\sqrt{\left(1-\left(m_{1}\right)^{2}\right)^{\lambda}-\left(1-\left(m_{1}\right)^{2}-\left(p_{1}\right)^{2}\right)^{\lambda}}, \sqrt{\left(1-\left(n_{1}\right)^{2}\right)^{\lambda}-\left(1-\left(n_{1}\right)^{2}-\left(r_{1}\right)^{2}\right)^{\lambda}}\right]}
\end{array}\right\} .
\end{aligned}
$$

IVSWAM operator is defined as follows:

$\operatorname{IVSWAM}_{w}\left(\widetilde{S}_{1}, \widetilde{S}_{2}, \ldots, \widetilde{S}_{n}\right)=w_{1} \widetilde{S}_{1} \otimes w_{2} \widetilde{S}_{2} \otimes \ldots \otimes w_{n} \widetilde{S}_{n}$

$$
=\left\{\begin{array}{c}
{\left[\sqrt{1-\prod_{i=1}^{n}\left(1-\left(k_{i}\right)^{2}\right)^{w_{i}}}, \sqrt{1-\prod_{i=1}^{n}\left(1-\left(l_{i}\right)^{2}\right)^{w_{i}}}\right],\left[\prod_{i=1}^{n}\left(m_{i}\right)^{w_{i}}, \prod_{i=1}^{n}\left(n_{i}\right)^{w_{i}}\right],} \\
{\left[\sqrt{\prod_{i=1}^{n}\left(1-\left(k_{i}\right)^{2}\right)^{w_{i}}-\prod_{i=1}^{n}\left(1-\left(k_{i}\right)^{2}-\left(p_{i}\right)^{2}\right)^{w_{i}}}, \sqrt{\prod_{i=1}^{n}\left(1-\left(l_{i}\right)^{2}\right)^{w_{i}}-\prod_{i=1}^{n}\left(1-\left(l_{i}\right)^{2}-\left(r_{i}\right)^{2}\right)^{w_{i}}}\right]}
\end{array}\right\} .
$$

Here, $w_{i} \epsilon[0,1] ; \sum_{i=1}^{n} w_{i}=1$.

Score and accuracy functions in ranking spherical fuzzy numbers are defined as in equations (9) and (10):

$$
\begin{aligned}
\operatorname{Score}\left(\widetilde{S}_{i}\right) & =\frac{\left(k_{i}\right)^{2}+\left(l_{i}\right)^{2}-\left(m_{i}\right)^{2}-\left(n_{i}\right)^{2}-\left(p_{i} / 2\right)^{2}-\left(r_{i} / 2\right)^{2}}{2}, \\
\operatorname{Accuracy}\left(\widetilde{S}_{i}\right) & =\frac{\left(k_{i}\right)^{2}+\left(l_{i}\right)^{2}+\left(m_{i}\right)^{2}+\left(n_{i}\right)^{2}+\left(p_{i}\right)^{2}+\left(r_{i}\right)^{2}}{2} .
\end{aligned}
$$


Here, it should be noted that $\widetilde{S}_{1}<\widetilde{S}_{2}$ if and only if Score $\left(\widetilde{S}_{1}\right)<\operatorname{Score}\left(\widetilde{S}_{2}\right) \quad$ or $\operatorname{Score}\left(\widetilde{S}_{1}\right)=\operatorname{Score}\left(\widetilde{S}_{2}\right) \quad$ and $\operatorname{Accuracy}\left(\widetilde{S}_{1}\right)<\operatorname{Accuracy}\left(\widetilde{S}_{2}\right)$.

3.2. Proposed Approach by Interval-Valued Spherical Fuzzy TOPSIS (IVSF-TOPSIS). A payoff matrix is mandatory to construct the decision-making process for all MCDM problems. Since the problem that this study has dealt with is related to the assessment of hospitals' preparedness against the COVID-19 pandemic, we have designed this matrix whose elements include the values of all alternatives with respect to each criterion under IVSFSs. Let $H=\left\{h_{1}, h_{2}, \ldots, h_{m}\right\} m \geq 2$ be a set of alternatives (for this study "hospitals"), $D=\left\{d_{1}, d_{2}, \ldots, d_{n}\right\}$ be a set of criteria set (for this study "components or dimensions of hospital preparedness assessment against COVID-19 pandemic"), and $w=\left\{w_{1}, w_{2}, \ldots, w_{n}\right\}$ be a set of criteria weights for this study "components' weights") that satisfy the conditions of $0 \leq w_{j} \leq 1$ and $\sum_{j=1}^{n} w_{j}=1$.

Steps of the proposed approach by IVSF-TOPSIS are described as follows:

Step 1: decision matrices are created. The construction of the importance weight vector carried out by each expert is also carried out in this step. In determining the ratings of experts (for this study, we refer to "hospital decision maker") regarding alternative hospitals with respect to the readiness components, the IVSFSs-based linguistic scale (adapted from [16]) given in Table 1 is used.

Let $D_{j}\left(H_{i}\right)=\left[\mu_{i j}^{L}(u), \mu_{i j}^{U}(u)\right],\left[v_{i j}^{L}(u), v_{i j}^{U}(u)\right],\left[\pi_{i j}^{L}(u)\right.$, $\left.\pi_{i j}^{U}(u)\right]$ denote the rating of a hospital with respect to a component. $X=D_{j}\left(H_{i}\right)_{m x n}$ refers to the decision matrix, which is defined as follows:

$$
X=D_{j}\left(H_{i}\right)_{m x n}=\left[\begin{array}{ccc}
{\left[\mu_{11}^{L}(u), \mu_{11}^{U}(u)\right],\left[v_{11}^{L}(u), v_{11}^{U}(u)\right],\left[\pi_{11}^{L}(u), \pi_{11}^{U}(u)\right]} & \cdots & {\left[\mu_{1 n}^{L}(u), \mu_{1 n}^{U}(u)\right],\left[v_{1 n}^{L}(u), v_{1 n}^{U}(u)\right],\left[\pi_{1 n}^{L}(u), \pi_{1 n}^{U}(u)\right]} \\
\vdots & \ddots & \vdots \\
{\left[\mu_{m 1}^{L}(u), \mu_{m 1}^{U}(u)\right],\left[v_{m 1}^{L}(u), v_{m 1}^{U}(u)\right],\left[\pi_{m 1}^{L}(u), \pi_{m 1}^{U}(u)\right]} & \cdots & {\left[\mu_{m n}^{L}(u), \mu_{m n}^{U}(u)\right],\left[v_{m n}^{L}(u), v_{m n}^{U}(u)\right],\left[\pi_{m n}^{L}(u), \pi_{m n}^{U}(u)\right]}
\end{array}\right] .
$$

Step 2: the decision matrices of each hospital decision maker, which are constructed under IVSFSs, are aggregated. Also, the aggregation regarding evaluations of hospital decision makers on component weight determination is performed in this step. We follow the aggregation procedure given in equation (8).

Step 3: the aggregated interval-valued spherical fuzzy decision matrix is converted into a weighted intervalvalued spherical fuzzy decision matrix using a multiplication operator which is given in equation (5).

Step 4: the weighted interval-valued spherical fuzzy decision matrix is defuzzified using an adaptable version of equation (9). It should be noted that the interval values of three membership functions are weighted interval-valued spherical fuzzy numbers, which are obtained in Step 3.
Step 5: the interval-valued spherical fuzzy positive ideal solution (IVSFPIS) and the interval-valued spherical fuzzy negative ideal solution (IVSFNIS) are calculated based on the score values obtained in Step 4. The formulas are given in equations (12) and (13) as follows:

$$
\begin{aligned}
H^{*} & =\left\{\left\{D_{j}, \max _{i} \operatorname{Score}\left(D_{j}\left(H_{i w}\right)\right) \mid j=1,2, \ldots, n\right\}\right\}, \\
H^{-} & =\left\{\left\{D_{j}, \min _{i} \operatorname{Score}\left(D_{j}\left(H_{i w}\right)\right) \mid j=1,2, \ldots, n\right\}\right\} .
\end{aligned}
$$

Step 6: the distances from IVSFPIS and IVSFNIS are calculated using equations (14) and (15) as follows:

$$
\begin{aligned}
d\left(H_{i j}, H_{j}^{*}\right)= & \frac{1}{4 n} \sum_{j=1}^{n}\left(\left|\left(\mu_{i j}^{L}\right)^{2}-\left(\mu_{j}^{*}\right)^{2}\right|+\left|\left(\mu_{i j}^{U}\right)^{2}-\left(\mu_{j}^{*}\right)^{2}\right|+\left|\left(v_{i j}^{L}\right)^{2}-\left(v_{j}^{*}\right)^{2}\right|+\left|\left(v_{i j}^{U}\right)^{2}-\left(v_{j}^{*}\right)^{2}\right|+\left|\left(\pi_{i j}^{L}\right)^{2}-\left(\pi_{j}^{*}\right)^{2}\right|\right. \\
& \left.+\left|\left(\pi_{i j}^{U}\right)^{2}-\left(\pi_{j}^{*}\right)^{2}\right|\right) \forall i, \\
d\left(H_{i j}, H_{j}^{-}\right)= & \frac{1}{4 n} \sum_{j=1}^{n}\left(\left|\left(\mu_{i j}^{L}\right)^{2}-\left(\mu_{j}^{-}\right)^{2}\right|+\left|\left(\mu_{i j}^{U}\right)^{2}-\left(\mu_{j}^{-}\right)^{2}\right|+\left|\left(v_{i j}^{L}\right)^{2}-\left(v_{j}^{-}\right)^{2}\right|+\left|\left(v_{i j}^{U}\right)^{2}-\left(v_{j}^{-}\right)^{2}\right|+\left|\left(\pi_{i j}^{L}\right)^{2}-\left(\pi_{j}^{-}\right)^{2}\right|\right. \\
& \left.+\left|\left(\pi_{i j}^{U}\right)^{2}-\left(\pi_{j}^{-}\right)^{2}\right|\right) \forall i .
\end{aligned}
$$


TABLE 1: The linguistic scale used in the assessment.

\begin{tabular}{|c|c|c|c|c|c|c|}
\hline \multirow{3}{*}{$\begin{array}{l}\text { Linguistic term } \\
\text { Absolutely good (AG) }\end{array}$} & \multicolumn{6}{|c|}{ Interval-valued spherical fuzzy number } \\
\hline & \multicolumn{2}{|c|}{$\left(\left[\mu \frac{L}{S_{i}}(u), \mu \underset{S_{i}}{U}(u)\right]\right.$} & \multicolumn{2}{|c|}{$\left[v{\underset{S_{i}}{L}}^{L}(u), v \underset{S_{i}}{U}(u)\right]$} & \multicolumn{2}{|c|}{$\left[\pi \underset{S_{i}}{L}(u), \pi{\underset{S}{S}}_{i}^{U}(u)\right]$} \\
\hline & 0.85 & 0.95 & 0.10 & 0.15 & 0.05 & 0.15 \\
\hline Very good (VG) & 0.75 & 0.85 & 0.15 & 0.20 & 0.15 & 0.20 \\
\hline Good $(\mathrm{G})$ & 0.65 & 0.75 & 0.20 & 0.25 & 0.20 & 0.25 \\
\hline Little good (LG) & 0.55 & 0.65 & 0.25 & 0.30 & 0.25 & 0.30 \\
\hline Equal (E) & 0.50 & 0.55 & 0.45 & 0.55 & 0.30 & 0.40 \\
\hline Little bad (LB) & 0.25 & 0.30 & 0.55 & 0.65 & 0.25 & 0.30 \\
\hline Bad (B) & 0.20 & 0.25 & 0.65 & 0.75 & 0.20 & 0.25 \\
\hline Very bad (VB) & 0.15 & 0.20 & & 0.85 & 0.15 & 0.20 \\
\hline Absolutely bad (AB) & 0.10 & 0.15 & 0.85 & 0.95 & 0.05 & 0.15 \\
\hline
\end{tabular}

Note. $\left[\mu \underset{S_{i}}{L}(u), \mu \underset{S_{i}}{U}(u)\right]$ corresponds to the lower and upper membership degree of an interval-valued spherical fuzzy number, respectively. $\left[v{\underset{S}{S}}_{i}(u), v \underset{S_{i}}{U}(u)\right]$

demonstrates the lower and upper nonmembership degree value of an interval-valued spherical fuzzy number, respectively. [ $\left.\pi \tilde{S}_{i}^{L}(u), \pi \underset{\tilde{S}_{i}}{U}(u)\right]$ refers to lower and upper hesitancy degree value of an interval-valued spherical fuzzy number, respectively.

Step 7: the closeness ratio (CR) of IVSF-TOPSIS is computed using the following equation:

$$
C R_{i}=\frac{d\left(H_{i j}, H_{j}^{-}\right)}{d\left(H_{i j}, H_{j}^{*}\right)+d\left(H_{i j}, H_{j}^{-}\right)} .
$$

Step 8: the last step prioritizes the ranking of each hospital to the descending order.

The demonstration flow of the proposed approach is shown in Figure 1. In Figure 1, a step-by-step flow is presented.

\section{Implementation of the Proposed Approach}

4.1. Preparation. In the preparation step of the implementation, the study's main aims, the adapted checklist, components and subcomponents, healthcare decision makers, and characteristics of assessed hospitals are explained. As stated in the previous sections, the aims of the study are as follows: (1) to assess hospitals in terms of readiness against COVID-19 pandemic concerning ninetyeight subcomponents in total under ten components and (2) to determine an index value for each assessed hospital considering all components and according to each component individually. Thus, an overall component-based index and an individual component-based index can be computed using the IVSF-TOPSIS procedure.

Regarding the adapted checklist, Figure 2 represents the components that the World Health Organization Regional Office for Europe published with the name of Hospital Readiness Checklist for COVID-19 in Copenhagen in 2020.

Under these ten components, there are several subcomponents. Each of them is explained in the WHO's checklist [5]. In the following, each subcomponent is described by highlighting its effects on hospital readiness against the COVID-19 disaster situation. For the first component of "surge capacity," eight subcomponents are determined as follows:
D1.1: availability of maximum patient admission capacity (this component refers not only to the total number of beds but also to the availability of human resources, areas that can be converted to intensive care, mechanical ventilators, and other resources)

D1.2: ability to use existing planning power and tools to predict the demand for hospital services in the time of the COVID-19 pandemic

D1.3: ability to expand inpatient capacity of the hospital (in terms of physical area, staff, equipment, and process)

D1.4: ability to identify potential gaps in providing health care by giving importance to intensive care (in cooperation with senior managers and neighboring hospitals)

D1.5: possibility to create additional capacity by determining an alternative location for the treatment of noncritical patients (e.g., sending less urgent patients home)

D1.6: availability of extra locations for conversion to healthcare units in coordination with the local authorities (e.g., hotels, schools, community centers, and gyms)

D1.7: cancellation flexibility of noncritical medical services (e.g., elective surgery) if necessary

D1.8: flexibility in adapting admissions and discharge criteria and possibility in prioritization of patients and clinical interventions according to available treatment capacity and demand

Regarding the second component of "infection prevention and control," fifteen subcomponents are determined as suitable to assess the readiness of hospitals. They are depicted as follows:

D2.1: availability of verbal instructions, informational posters, cards, hand hygiene stations (water, soap, paper towel, and alcohol hand rub), and waste bins at strategic locations across the hospital to provide healthcare workers, patients, and visitors' awareness 


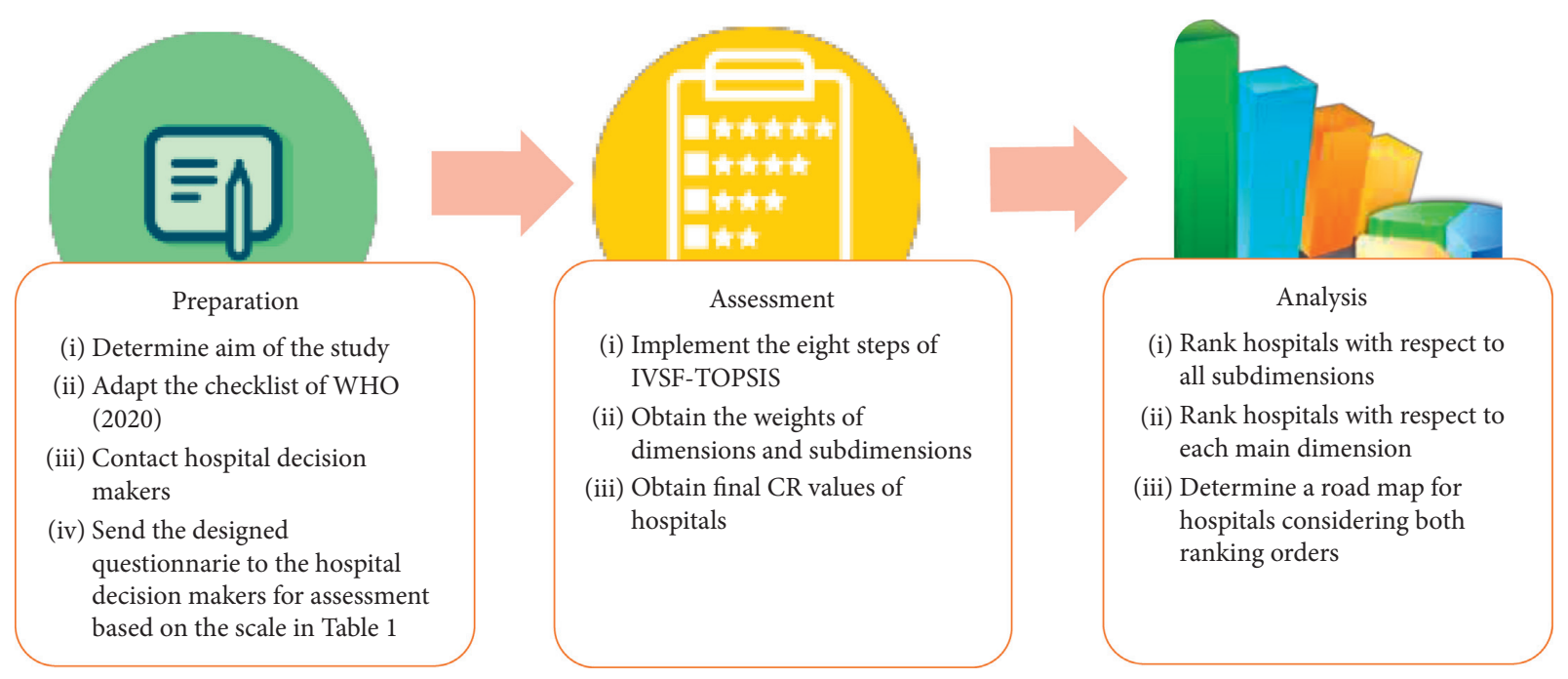

Figure 1: The flow of the proposed approach.

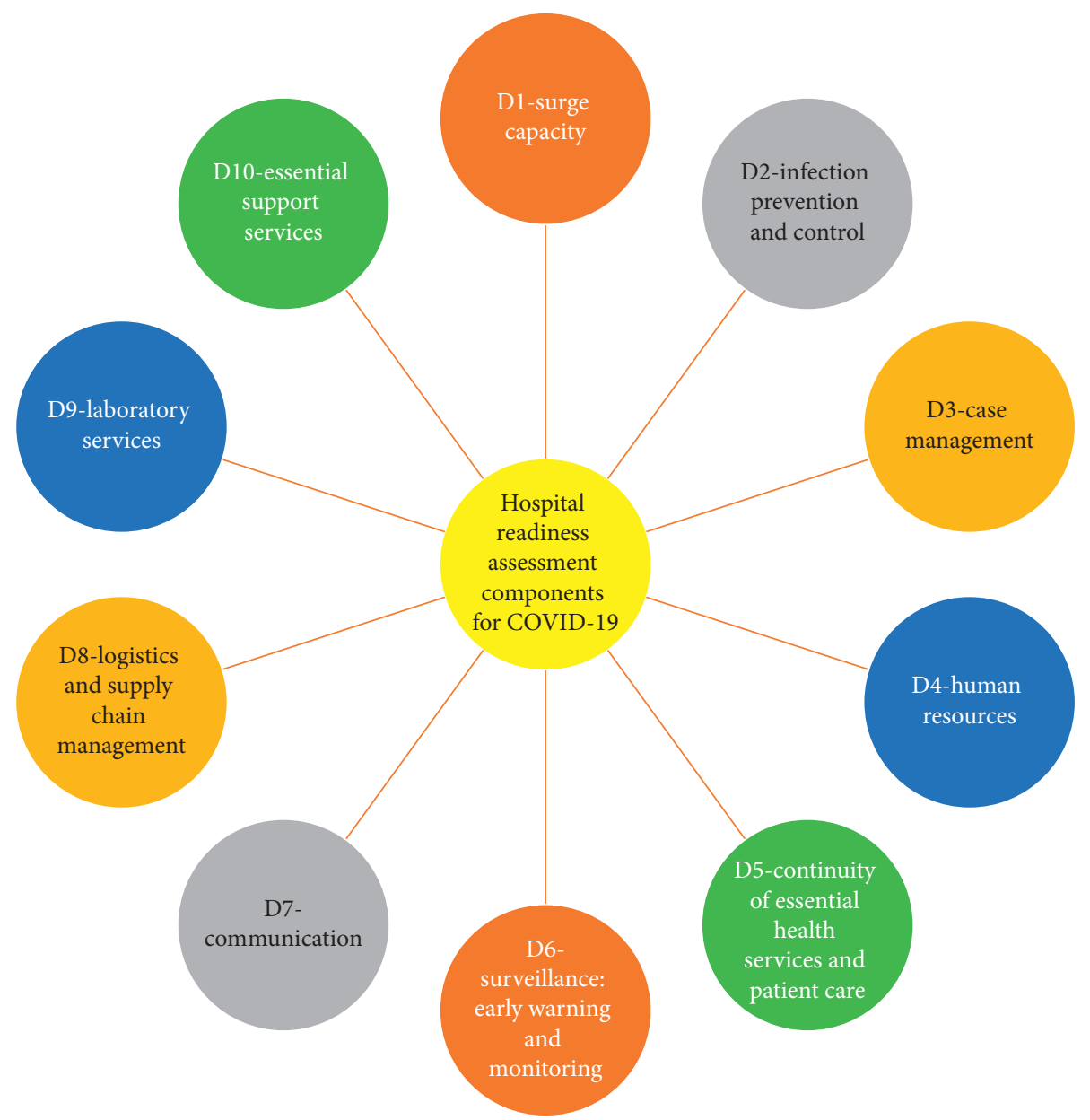

FIgURE 2: Hospital readiness assessment components for COVID-19. 
D2.2: status of the application of standard measures for all patients by healthcare professionals

D2.3: continuation status of droplet and contact measures for suspected or confirmed COVID-19 cases until the patient is asymptomatic

D2.4: possibility to place patients in single rooms with adequate ventilation (grouping of patients suspected of having COVID-19 in the absence of single rooms and nonplacement of the suspect and confirmed cases in mixed)

D2.5: applying a one-meter distance rule between beds regardless of whether patients are suspected of having COVID-19

D2.6: follow-up of equipment being disposable or cleaning and disinfection in case of sharing

D2.7: routine cleaning and disinfection of the surfaces that the patient touches (compliance with the standards and guidelines recommended for COVID-19, routine cleaning, and disinfection of the ambulance)

D2.8: health workers' application to droplet and contact measures before entering the room where suspected or confirmed COVID-19 patients are placed

D2.9: application of airborne precautions for aerosolgenerating procedures, such as tracheal intubation, noninvasive ventilation, tracheotomy, cardiopulmonary resuscitation, manual ventilation before intubation, bronchoscopy, collection of nasopharyngeal swap/aspirate, and an autopsy by health workers

D2.10: possibility of appointment of a healthcare team to look specifically at suspect or approved cases to reduce the risk of contamination

D2.11: easy access of adequate personal protective equipment (PPE) (i.e., medical/surgical masks, N95/ FFP2 respirators, gloves, gowns, and eye protection) for staff

D2.12: compliance with the rule of not moving and transporting patients unless medically necessary

D2.13: compliance with the rule of limiting visitors to only those crucial for patient support

D2.14: keeping records of all people entering the patient's room, including all staff and visitors

D2.15: managing ability of laboratory specimens, laundry, food service utensils, and medical waste following safe routine procedures according to infection prevention and control (IPC) guidelines

The "case management" component is another main component of this decision-making problem and has seventeen subcomponents as identified below.

D3.1: availability of mechanisms to implement triage, early recognition, and source control (isolating patients with suspected COVID-19)

D3.2: availability of a well-equipped triage station at the entrance of the hospital, supported by trained staff
D3.3: the ability of healthcare professionals to have a high level of clinical suspicion

D3.4: ability to designate a special waiting and examination area for individuals applying with COVID-19 symptoms depending on the algorithm of the Republic of Turkey Ministry of Health

D3.5: ability to create additional areas for triage of patients in tents set up outside the hospital

D3.6: appointment of a triage supervisor authorized for the whole triage process

D3.7: ability to create a triage algorithm for the detection of acute respiratory infection cases

D3.8: applicability of standard and droplet measures at all times

D3.9: applicability of the hospital strategy for admission, internal transfer, referral, and discharge of patients with severe acute respiratory infections (ARIs)

D3.10: consideration of home care for mild cases of COVID-19 ARI in patients with no comorbidities

D3.11: consideration of hospital admission for cases of COVID-19 ARI in patients with comorbidities

D3.12: availability of staffed beds for the admission of severe COVID-19 ARI cases requiring supportive care

D3.13: ability to continuously monitor vital signs and oxygen saturation

D3.14: availability of oxygen and sufficient sedation for intubated patients by means of respiratory support

D3.15: patient care by following national and international guidelines (status of all staff aware of national and international guidelines for case management)

D3.16: communication status to hospital staff responsible for admission criteria and processes related to triage logistics (e.g., location and entry/exit routes)

D3.17: availability of awareness of healthcare workers regarding the protocols for off-license use of medicines, which should be done against observational trial protocol, and outcomes recorded against standardized variables

The fourth component concerns human resources and their management. The subcomponents under this heading are as follows:

\section{D4.1: update of the personnel contact list}

D4.2: estimation ability of staff absenteeism in advance and continuous monitoring ability

D4.3: availability of a clear policy (the policy should define levels of exposure) to monitor and manage staff suspected or confirmed of having COVID-19 or who have had exposure to a confirmed, probable, or suspected COVID-19 patient

D4.4: minimum number of healthcare professionals and other hospital staff who will ensure the adequate or proper functioning of the treatment unit or service 
D4.5: prioritization of personnel needs by the unit or service and distribution of personnel accordingly

D4.6: ability to collect and train additional staff based on expected needs

D4.7: ability of ward staff to work in high demand areas (e.g., infectious disease department, emergency department, and intensive care unit)

D4.8: ability in providing training and exercises to ensure staff competency and safety

D4.9: availability of domestic support measures that could enhance staff flexibility for shift work and longer working hours and define off work time for recuperation

D4.10: formation of psychosocial support teams for staff and patient families

D4.11: consideration of liability, insurance, and temporary license issues for personnel working outside of their specialties

D4.12: availability of volunteer workers' policies (vetting, accepting, rejecting, liability issues, etc.)

D4.13: reassignment of staff at high risk for complications of COVID-19 acute respiratory infection

The fifth component named as "continuity of essential health services and patient care" has only four subcomponents, as explained below.

D5.1: formation of a list showing priority relationship for all hospital services

D5.2: the ability of hospital to determine and maintain the services that should be provided at all times and all conditions

D5.3: to identify human and logistics resources to ensure the continuity of hospital services

D5.4: easiness in being familiar with preparedness mechanisms across the local healthcare network for disasters or mass casualty incidents

The sixth component "surveillance" is described as early warning and monitoring. Under this component, there are nine subcomponents.

D6.1: appointment of an epidemiologist responsible for early warning activities of the hospital

D6.2: identification of information to be collected and definition of intended use

D6.3: encouraging the reporting of COVID-19 incidents by communicating with in-hospital and public health management

D6.4: ability to establish data collection and reporting mechanisms by following national health policies

D6.5: complying with standardized case definitions, recommended levels of surveillance, and triggers

D6.6: prompt investigation reports of unusual health events by healthcare professionals
D6.7: prompt distribution of information to hospital clinicians, front-line workers, and other relevant decision makers obtained through the investigation of unusual events

D6.8: processing of COVID-19 patients' tests by national procedures and algorithms of the Ministry of Health

D6.9: ensuring all staff are conversant with standardized case definitions, recommended levels of surveillance, and triggers by the national criteria

"Communication" also has a substantial impact on hospital readiness assessment against COVID-19. This component contains eight subcomponents as below:

D7.1: availability of communication mechanisms between the hospital's administrative management

D7.2: availability of roles and responsibilities of hospital staff in the management of COVID-19 under the Incident Management System (IMS)

D7.3: communication of all decisions on triage, patient prioritization, infection prevention and control, case management, and hospital epidemiology to all relevant staff and stakeholders

D7.4: collecting, processing, and reporting information to public health officials

D7.5: preparation of messages dealing with various scenarios related to COVID-19

D7.6: appointment of a spokesperson who coordinates communication with the public, the media, and health authorities

D7.7: ensuring reliable and sustainable primary and backup communication systems and providing access to updated contact lists

D7.8: being familiar with referral mechanisms established at the national level and related communication mechanisms

The component of "logistics and supply chain management" concerns the availability of essential equipment and supplies, including pharmaceuticals. It has several subcomponents regarding effective resource and facility management during the COVID-19 pandemic. These are as follows:

D8.1: developing/maintaining an updated inventory of all equipment, supplies, and pharmaceuticals; availability of a shortage alert and reordering mechanism

D8.2: estimation of the consumption of required equipment, materials, and medicines according to the most likely pandemic scenario

D8.3: ability to consult with the authority to ensure uninterrupted supply of essential medicine and supplies

D8.4: quality assessment and requesting a quality certificate before purchasing 
D8.5: agreements with vendors to ensure resource availability and immediate delivery in times of shortage D8.6: storage of additional materials and physical availability in the hospital for this

D8.7: stocking ability of fundamental supplies and medicine based on recommended guidelines

D8.8: defining the role of the hospital pharmacy in providing medicines for the treatment

D8.9: finding a mechanism for rapid maintenance and repair of essential equipment for basic services

D8.10: coordination of an emergency transport strategy to be created to ensure uninterrupted patient transfers

D8.11: availability of a policy in place for managing donations of medical supplies, food for staff, etc.

The ninth and tenth components, "laboratory services" and "essential support services," have seven components per each, as investigated in detail below.

D9.1: continuous availability of necessary laboratory testing

D9.2: identifying essential laboratory supplies and resources and their continuous availability

D9.3: identifying backup laboratory personnel and/or alternative laboratory services

D9.4: prioritizing testing for respiratory viruses (e.g., COVID-19)

D9.5: availability of a laboratory referral pathway for the identification, confirmation, and monitoring of COVID-19

D9.6: establishing and training staff on packaging and transportation procedures for specimen referrals

D9.7: availability of mechanisms for the prompt provision of laboratory data to the physicians and health authorities

D10.1: estimating the additional supplies required by the support services and introducing a mechanism to ensure the continuous availability of these supplies

D10.2: ability of support services to cope with demand boom

D10.3: anticipating the impact of COVID-19 on hospital food supplies; taking proactive measures

D10.4: availability of backup arrangements for water, power, and oxygen

D10.5: availability of hospital security in managing security and safety of hospital

D10.6: availability of an area for a temporary morgue and the sufficient body bags and shroud packs

D10.7: formulation of a postmortem care contingency plan with proper stakeholders

After adapting the components and related subcomponents in this regard, healthcare decision makers are determined. They are then contacted to fill the questionnaire, which is designed for the decision-making problem. The team consists of hospital managers who know the hospital's operations well and follow all of the activities in most of his/ her time during the COVID-19 pandemic. The team's evaluation forms were sent on April 20, 2020, and forms were received on May 10, 2020.

This study is conducted in three hospitals serving approximately 700,000 people per year. The hospitals are coded as $\mathrm{H} 1, \mathrm{H} 2$, and $\mathrm{H} 3 . \mathrm{H} 1$ is one of the oldest hospitals in the region. This hospital has been serving COVID-19 patients, approximately $10 \%$ of its total admission capacity. $\mathrm{H} 2$ is a hospital that serves as a private hospital outside the city center. As a result of the decision taken by the Republic of Turkey Ministry of Health, the number of patients increased considerably with the diagnosis and treatment of pandemic cases free of charge during the pandemic. $\mathrm{H} 3$ is a relatively newly established state hospital in the region. It has served as the main hospital in the fight against COVID-19 in the region. During the peak time of the epidemic, it has operated close to its full capacity. In addition, this hospital is superior to other hospitals in the region in terms of bed capacity, number of intensive care beds, and number of respirators.

4.2. Assessment. In the first step of IVSF-TOPSIS, a decision matrix is constructed. Three hospital decision makers have rated the hospitals with respect to the ninety-nine subcomponents using the linguistic scale in Table 1. At the same time, they have rated the subcomponents using the same scale to obtain importance weights. It is indeed the second step of the approach. Also, the aggregation is performed in this step using an IVSWAM operator. Table 2 provides the obtained final weights of these subcomponents in IVSFSs.

As an example, Figure 3 shows the calculation process to obtain the weight of the D1.1 subcomponent from the expert evaluations in IVSFS.

The aggregation of the decision matrix, which is constructed under IVSFSs, is then made. As an example of this, Figure 4 shows the process to obtain weighted IVSF values of $\mathrm{H} 1, \mathrm{H} 2$, and $\mathrm{H} 3$ hospitals against the D1.1 subcomponent from the expert evaluations.

In the third step, the aggregated decision matrix is converted into a weighted interval-valued spherical fuzzy decision matrix by considering the weight values obtained in Table 2. As an example, Figure 5 demonstrates the process to get a weighted aggregated decision matrix in IVSFSs using equation (5).

Following this step, the weighted interval-valued spherical fuzzy decision matrix is defuzzified in the fourth step. In the fifth and sixth steps, the IVSFPIS and IVSFNIS values based on the score functions and separation measures from these two values are calculated. Finally, the CR for each hospital is obtained, and the prioritization is performed. Figure 6 presents the CR values for the hospitals.

The CR values of IVSF-TOPSIS indicate that the readiest hospital among COVID-19 is H1. It has an IVSF-TOPSIS CR value of 0.79 . This hospital is an educational and research hospital and serves many admissions during the pandemic time. On the other side, $\mathrm{H} 2$ has a value of 0.44 . $\mathrm{H} 3$ has the lowest CR value of 0.24 . The least ready hospital is $\mathrm{H} 3$. 
TABLE 2: Obtained subcomponents' weights in IVSFS.

\begin{tabular}{|c|c|}
\hline Subcomponent & Weight in IVSFS \\
\hline D1.1 & $([0.63,0.73],[0.21,0.26],[0.21,0.26])$ \\
\hline D1.2 & $([0.55,0.65],[0.25,0.3],[0.25,0.3])$ \\
\hline D1.3 & $([0.24,0.29],[0.57,0.67],[0.24,0.29])$ \\
\hline D1.4 & $([0.25,0.3],[0.55,0.65],[0.25,0.3])$ \\
\hline D1.5 & $([0.24,0.29],[0.57,0.67],[0.24,0.29])$ \\
\hline D1.6 & $([0.5,0.55],[0.45,0.55],[0.3,0.4])$ \\
\hline D1.7 & $([0.54,0.63],[0.28,0.34],[0.26,0.32])$ \\
\hline D1.8 & $([0.5,0.55],[0.45,0.55],[0.3,0.4])$ \\
\hline $\mathrm{D} 2.1$ & $([0.5,0.55],[0.45,0.55],[0.3,0.4])$ \\
\hline $\mathrm{D} 2.2$ & $([0.83,0.94],[0.11,0.16],[0.07,0.16])$ \\
\hline $\mathrm{D} 2.3$ & $([0.85,0.95],[0.1,0.15],[0.05,0.15])$ \\
\hline $\mathrm{D} 2.4$ & $([0.83,0.94],[0.11,0.16],[0.07,0.16])$ \\
\hline $\mathrm{D} 2.5$ & $([0.83,0.94],[0.11,0.16],[0.07,0.16])$ \\
\hline D2.6 & $([0.83,0.94],[0.11,0.16],[0.07,0.16])$ \\
\hline $\mathrm{D} 2.7$ & $([0.85,0.95],[0.1,0.15],[0.05,0.15])$ \\
\hline $\mathrm{D} 2.8$ & $([0.85,0.95],[0.1,0.15],[0.05,0.15])$ \\
\hline D2.9 & $([0.85,0.95],[0.1,0.15],[0.05,0.15])$ \\
\hline $\mathrm{D} 2.10$ & $([0.85,0.95],[0.1,0.15],[0.05,0.15])$ \\
\hline $\mathrm{D} 2.11$ & $([0.83,0.94],[0.11,0.16],[0.07,0.16])$ \\
\hline $\mathrm{D} 2.12$ & $([0.6,0.71],[0.23,0.28],[0.23,0.28])$ \\
\hline $\mathrm{D} 2.13$ & $([0.57,0.67],[0.24,0.29],[0.24,0.29])$ \\
\hline $\mathrm{D} 2.14$ & $([0.55,0.65],[0.25,0.3],[0.25,0.3])$ \\
\hline D2.15 & $([0.82,0.93],[0.11,0.17],[0.08,0.17])$ \\
\hline D3.1 & $([0.85,0.95],[0.1,0.15],[0.05,0.15])$ \\
\hline D3.2 & $([0.77,0.88],[0.14,0.19],[0.13,0.19])$ \\
\hline D3.3 & $([0.77,0.88],[0.14,0.19],[0.13,0.19])$ \\
\hline D3.4 & $([0.83,0.94],[0.11,0.16],[0.07,0.16])$ \\
\hline D3.5 & $([0.83,0.94],[0.11,0.16],[0.07,0.16])$ \\
\hline D3.6 & $([0.75,0.85],[0.15,0.2],[0.15,0.2])$ \\
\hline D3.7 & $([0.75,0.85],[0.15,0.2],[0.15,0.2])$ \\
\hline D3.8 & $([0.75,0.85],[0.15,0.2],[0.15,0.2])$ \\
\hline D3.9 & $([0.6,0.71],[0.23,0.28],[0.23,0.28])$ \\
\hline D3.10 & $([0.55,0.65],[0.25,0.3],[0.25,0.3])$ \\
\hline D3.11 & $([0.54,0.63],[0.28,0.34],[0.26,0.32])$ \\
\hline D3.12 & $([0.54,0.63],[0.28,0.34],[0.26,0.32])$ \\
\hline D3.13 & $([0.83,0.94],[0.11,0.16],[0.07,0.16])$ \\
\hline D3.14 & $([0.83,0.94],[0.11,0.16],[0.07,0.16])$ \\
\hline D3.15 & $([0.83,0.94],[0.11,0.16],[0.07,0.16])$ \\
\hline D3.16 & $([0.75,0.85],[0.15,0.2],[0.15,0.2])$ \\
\hline D3.17 & $([0.67,0.77],[0.19,0.24],[0.19,0.24])$ \\
\hline D4.1 & $([0.67,0.77],[0.19,0.24],[0.19,0.24])$ \\
\hline D4.2 & $([0.67,0.77],[0.19,0.24],[0.19,0.24])$ \\
\hline D4.3 & $([0.83,0.94],[0.11,0.16],[0.07,0.16])$ \\
\hline D4.4 & $([0.83,0.94],[0.11,0.16],[0.07,0.16])$ \\
\hline D4.5 & $([0.72,0.82],[0.17,0.22],[0.17,0.22])$ \\
\hline D4.6 & $([0.55,0.65],[0.25,0.3],[0.25,0.3])$ \\
\hline D4.7 & $([0.55,0.65],[0.25,0.3],[0.25,0.3])$ \\
\hline D4.8 & $([0.57,0.67],[0.24,0.29],[0.24,0.29])$ \\
\hline D4.9 & $([0.54,0.6],[0.38,0.47],[0.28,0.37])$ \\
\hline $\mathrm{D} 4.10$ & $([0.24,0.29],[0.57,0.67],[0.24,0.29])$ \\
\hline $\mathrm{D} 4.11$ & $([0.2,0.25],[0.65,0.75],[0.2,0.25])$ \\
\hline $\mathrm{D} 4.12$ & $([0.24,0.29],[0.57,0.67],[0.24,0.29])$ \\
\hline $\mathrm{D} 4.13$ & $([0.63,0.73],[0.21,0.26],[0.21,0.26])$ \\
\hline D5.1 & $([0.72,0.82],[0.17,0.22],[0.17,0.22])$ \\
\hline D5.2 & $([0.55,0.65],[0.25,0.3],[0.25,0.3])$ \\
\hline D5.3 & $([0.63,0.73],[0.21,0.26],[0.21,0.26])$ \\
\hline D5.4 & $([0.51,0.57],[0.4,0.49],[0.29,0.38])$ \\
\hline D6.1 & $([0.55,0.65],[0.25,0.3],[0.25,0.3])$ \\
\hline D6.2 & $([0.51,0.57],[0.4,0.49],[0.29,0.38])$ \\
\hline D6.3 & $([0.51,0.57],[0.4,0.49],[0.29,0.38])$ \\
\hline
\end{tabular}

TABle 2: Continued.

\begin{tabular}{|c|c|}
\hline Subcomponent & Weight in IVSFS \\
\hline D6.4 & $([0.51,0.57],[0.4,0.49],[0.29,0.38])$ \\
\hline D6.5 & $([0.51,0.57],[0.4,0.49],[0.29,0.38])$ \\
\hline D6.6 & $([0.63,0.73],[0.21,0.26],[0.21,0.26])$ \\
\hline D6.7 & $([0.67,0.77],[0.19,0.24],[0.19,0.24])$ \\
\hline D6.8 & $([0.83,0.94],[0.11,0.16],[0.07,0.16])$ \\
\hline D6.9 & $([0.83,0.94],[0.11,0.16],[0.07,0.16])$ \\
\hline D7.1 & $([0.6,0.71],[0.23,0.28],[0.23,0.28])$ \\
\hline D7.2 & $([0.75,0.85],[0.15,0.2],[0.15,0.2])$ \\
\hline D7.3 & $([0.67,0.77],[0.19,0.24],[0.19,0.24])$ \\
\hline D7.4 & $([0.67,0.77],[0.19,0.24],[0.19,0.24])$ \\
\hline D7.5 & $([0.75,0.85],[0.15,0.2],[0.15,0.2])$ \\
\hline D7.6 & $([0.67,0.77],[0.19,0.24],[0.19,0.24])$ \\
\hline D7.7 & $([0.67,0.77],[0.19,0.24],[0.19,0.24])$ \\
\hline D7.8 & $([0.51,0.57],[0.4,0.49],[0.29,0.38])$ \\
\hline D8.1 & $([0.72,0.82],[0.17,0.22],[0.17,0.22])$ \\
\hline D8.2 & $([0.55,0.65],[0.25,0.3],[0.25,0.3])$ \\
\hline D8.3 & $([0.55,0.65],[0.25,0.3],[0.25,0.3])$ \\
\hline D8.4 & $([0.51,0.57],[0.4,0.49],[0.29,0.38])$ \\
\hline D8.5 & $([0.72,0.82],[0.17,0.22],[0.17,0.22])$ \\
\hline D8.6 & $([0.72,0.82],[0.17,0.22],[0.17,0.22])$ \\
\hline D8.7 & $([0.77,0.88],[0.14,0.19],[0.13,0.19])$ \\
\hline D8.8 & $([0.77,0.88],[0.14,0.19],[0.13,0.19])$ \\
\hline D8.9 & $([0.77,0.88],[0.14,0.19],[0.13,0.19])$ \\
\hline D8.10 & $([0.77,0.88],[0.14,0.19],[0.13,0.19])$ \\
\hline D8.11 & $([0.83,0.94],[0.11,0.16],[0.07,0.16])$ \\
\hline D9.1 & $([0.83,0.94],[0.11,0.16],[0.07,0.16])$ \\
\hline D9.2 & $([0.83,0.94],[0.11,0.16],[0.07,0.16])$ \\
\hline D9.3 & $([0.83,0.94],[0.11,0.16],[0.07,0.16])$ \\
\hline D9.4 & $([0.83,0.94],[0.11,0.16],[0.07,0.16])$ \\
\hline D9.5 & $([0.83,0.94],[0.11,0.16],[0.07,0.16])$ \\
\hline D9.6 & $([0.83,0.94],[0.11,0.16],[0.07,0.16])$ \\
\hline D9.7 & $([0.77,0.88],[0.14,0.19],[0.13,0.19])$ \\
\hline D10.1 & $([0.51,0.57],[0.4,0.49],[0.29,0.38])$ \\
\hline D10.2 & $([0.51,0.57],[0.4,0.49],[0.29,0.38])$ \\
\hline D10.3 & $([0.19,0.24],[0.67,0.77],[0.19,0.24])$ \\
\hline D10.4 & $([0.72,0.82],[0.19,0.24],[0.18,0.23])$ \\
\hline D10.5 & $([0.23,0.28],[0.59,0.69],[0.23,0.28])$ \\
\hline D10.6 & $([0.19,0.24],[0.67,0.77],[0.19,0.24])$ \\
\hline D10.7 & $([0.51,0.57],[0.4,0.49],[0.29,0.38])$ \\
\hline
\end{tabular}

4.3. Analysis. This section provides the additional analysis results, which show a secondary ranking of hospitals with respect to main components (10 components, as mentioned in the WHO's adapted checklist). This follow-up analysis may help hospital executives on a regional and national scale determine in which aspects hospitals are ready and in what aspects hospitals are not prepared for pandemics. Figures 7 and 8 show detailed analysis results and ranking orders of hospitals against the COVID-19 fight, respectively.

The results are based on the $\mathrm{D} 1$ dimension, and hospital rankings are obtained as $\mathrm{H} 1, \mathrm{H} 3$, and $\mathrm{H} 2$, respectively. The relatively new hospital "H3," although superior in terms of technical possibilities, is ranked in the second position. It can be concluded that for the surge competence, not only the infrastructure is sufficient, but also a strong health team is needed. Although hospital " $\mathrm{H} 2$ " has a relatively excellent physician staff because it is a private hospital, it has been ranked in the second position due to lack of infrastructure 


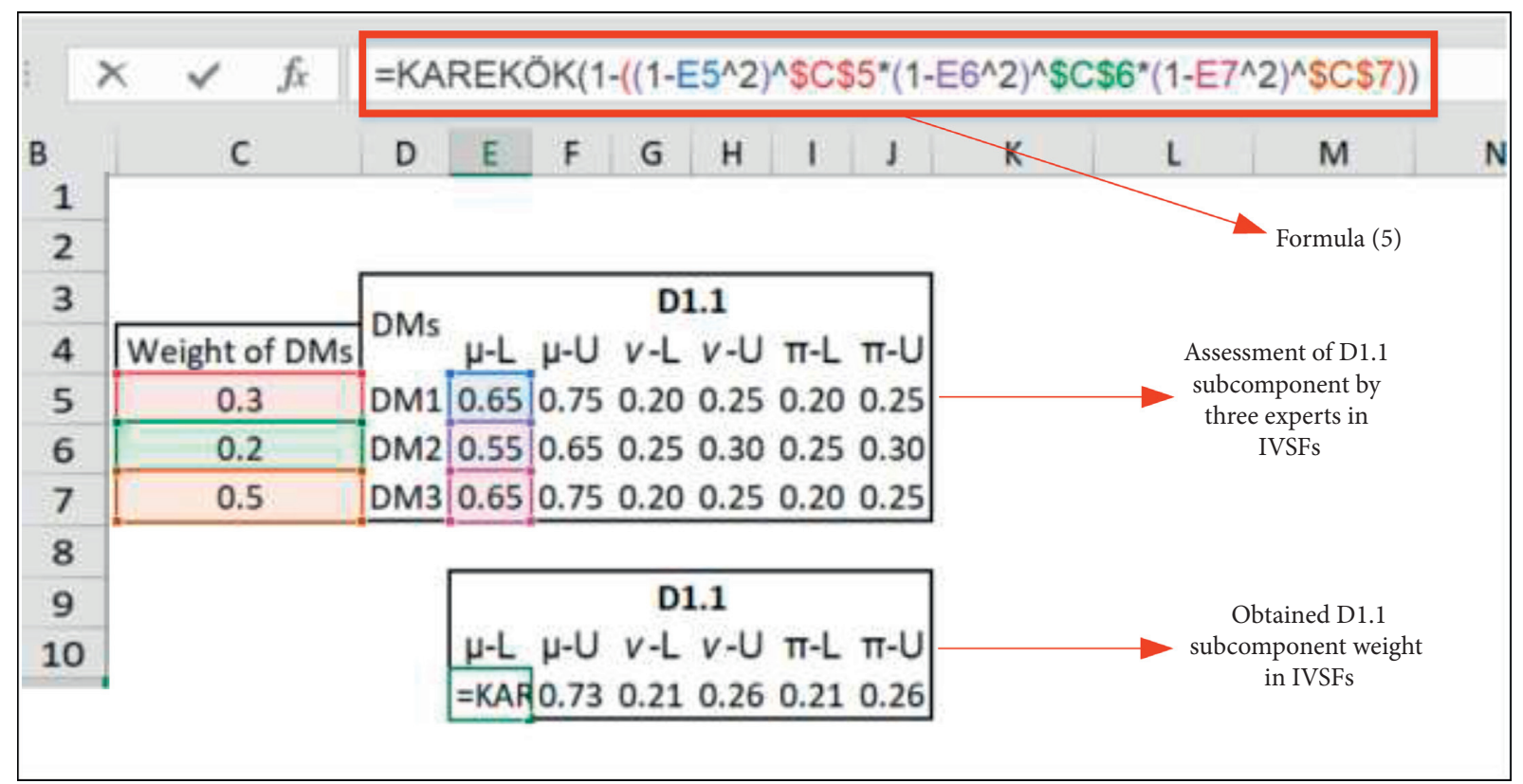

FIGURE 3: An example of the process to obtain the weight of D1.1 subcomponent from the expert evaluations in IVSFS.

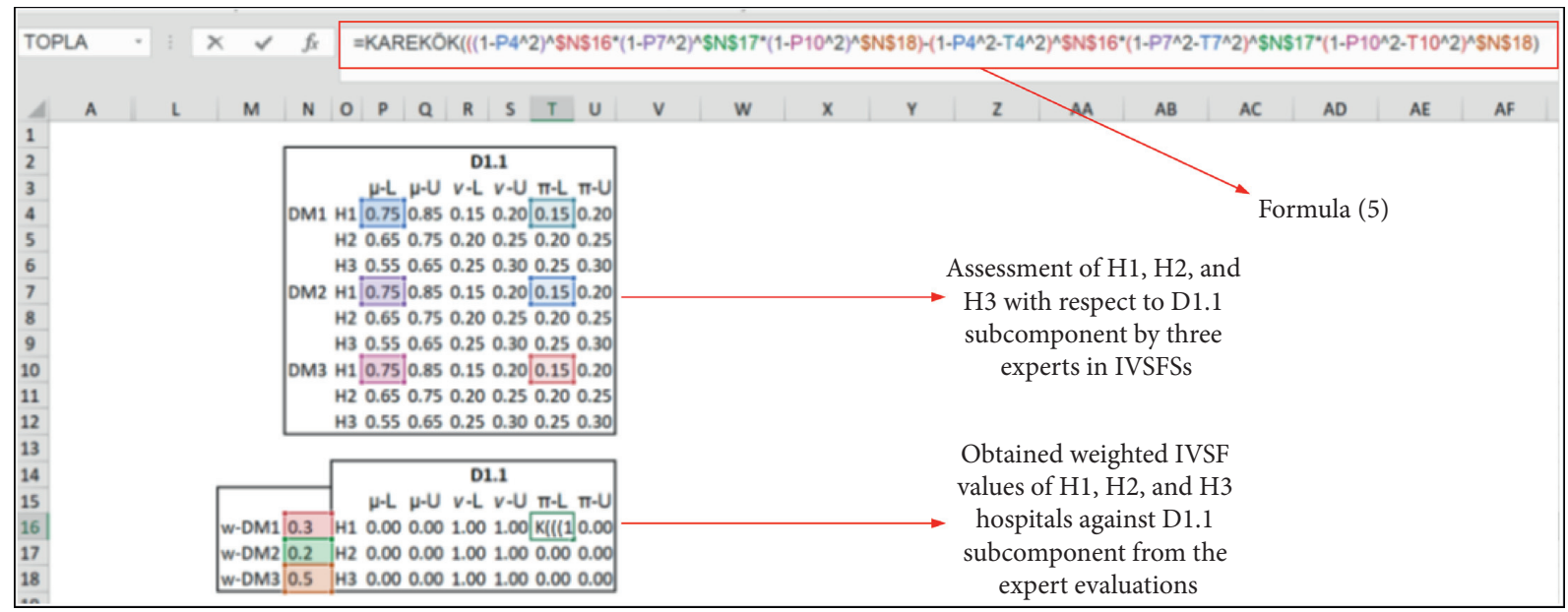

FIgURE 4: An example of the process to obtain weighted IVSF values of H1, H2, and H3 hospitals against D1.1 subcomponent from the expert evaluations.

and equipment. As a result of the evaluation for the D2 dimension, the hospitals are listed as $\mathrm{H} 3, \mathrm{H} 2$, and $\mathrm{H} 1$, respectively.

H3 is the hospital that treats the most COVID-19 patients in the region. It can be said that the extra training given to the hospital staff of $\mathrm{H} 3$ during the epidemic is beneficial. It can also be noted that as the number of patients increases, the awareness of protection from infection increases, too. The ranking order of " $\mathrm{H} 2, \mathrm{H} 1, \mathrm{H} 3$ " is obtained based on the D4 dimension. This ranking evokes the rate of healthcare workers per patient. Increasing the number of staff may enable the D4 dimension to be improved.

The evaluation results of the dimensions "D3, D5, D6, D7, D8, and D9" yield the same ranking order $(\mathrm{H} 1, \mathrm{H} 2, \mathrm{H} 3)$. This ranking has the same order as the time the hospital has been operating. There is a close relationship between case management, continuity of health services, early warning and monitoring, communication capability, supply chain management, laboratory services, and the institutional structure of the hospital and duration of the operation. In addition, these parameters are not related to the novelty and adequacy of hospital equipment but are closely related to the number and transformation of health personnel. It should be made attractive for the qualified health personnel to operate in the hospital to create a pandemic-prepared hospital within the scope of the dimensions of D5, D6, D7, D8, and D9. Job satisfaction of the staff should also be increased. The ranking in the evaluation made for the D10 dimension has been obtained as $\mathrm{H} 2, \mathrm{H} 1$, and $\mathrm{H} 3$. Transportation facilities at $\mathrm{H} 2$ and $\mathrm{H} 1$, which are in the top two in essential support 


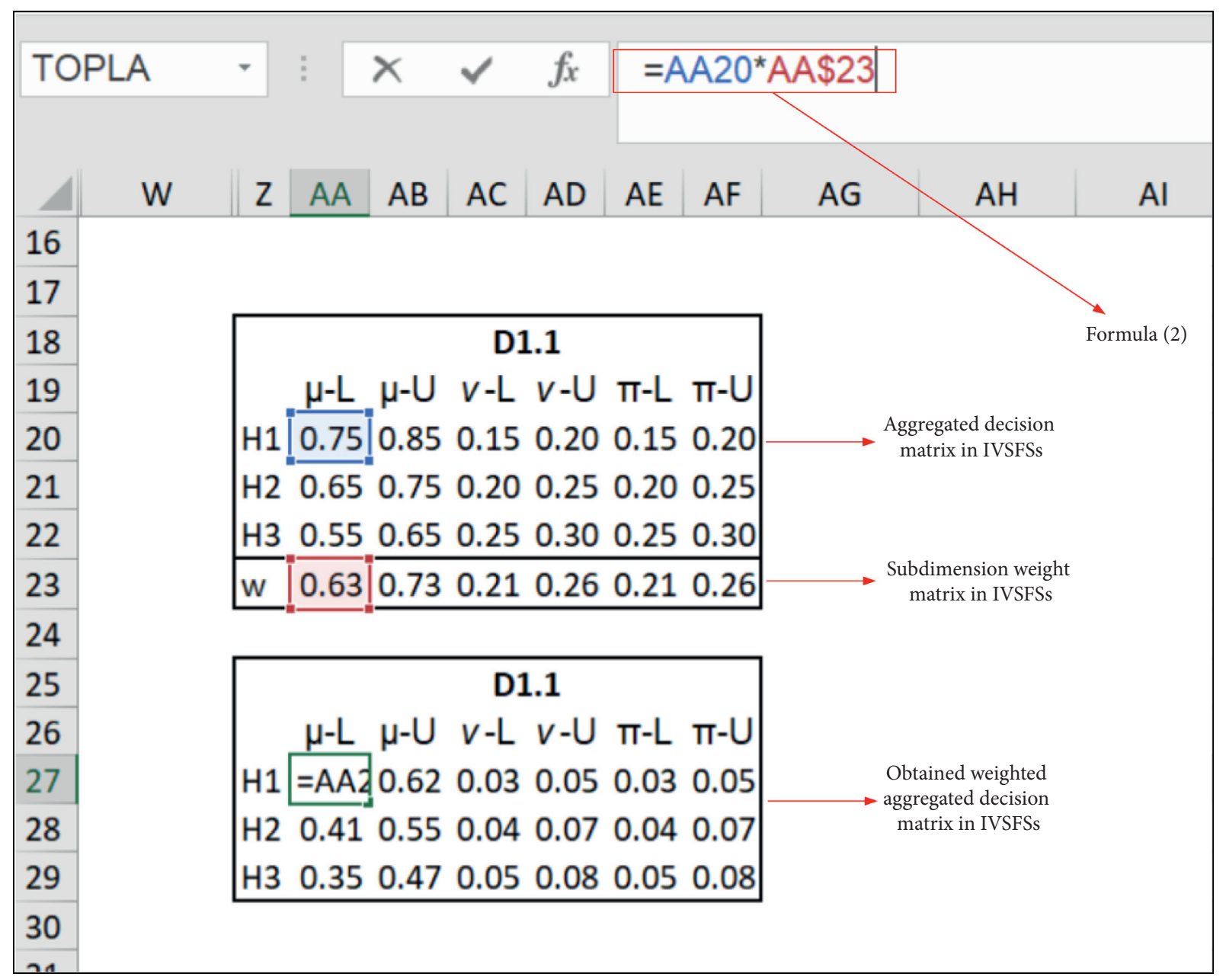

Figure 5: An example of the process to obtain a weighted aggregated decision matrix in IVSFSs using equation (5).

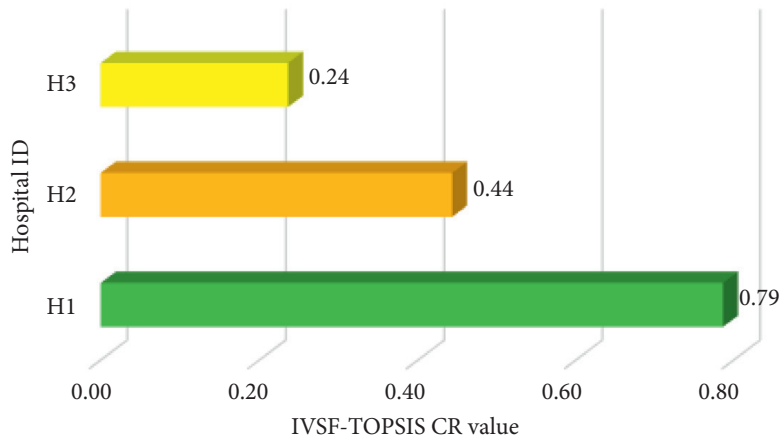

FIGURE 6: Obtained IVSF-TOPSIS CR values of hospitals.

services, are high. The D10 dimension has a tight relationship with transport and logistics capabilities. The condition of meeting the D10 dimension shows a relationship with the location of the hospital.

A comparative study has also been studied to demonstrate the solidity of the proposed approach. For this aim, the results of the proposed approach by IVSF-TOPSIS and traditional F-TOPSIS by Chen [54] are compared. Aggregated experts' evaluations are transformed into triangular fuzzy numbers, and computational steps in Chen [54] are followed. The variations in final $\mathrm{CR}$ values and hospital rankings are then observed. The results are shown in Table 3.

Table 3 shows that hospital rankings are the same by both approaches according to the nine of ten analysis bases. The only different ranking was obtained in the analysis based on the D10 dimension. When we compare the results obtained with both approaches according to the CR values, we observe close results. Since we do not observe significant differences 


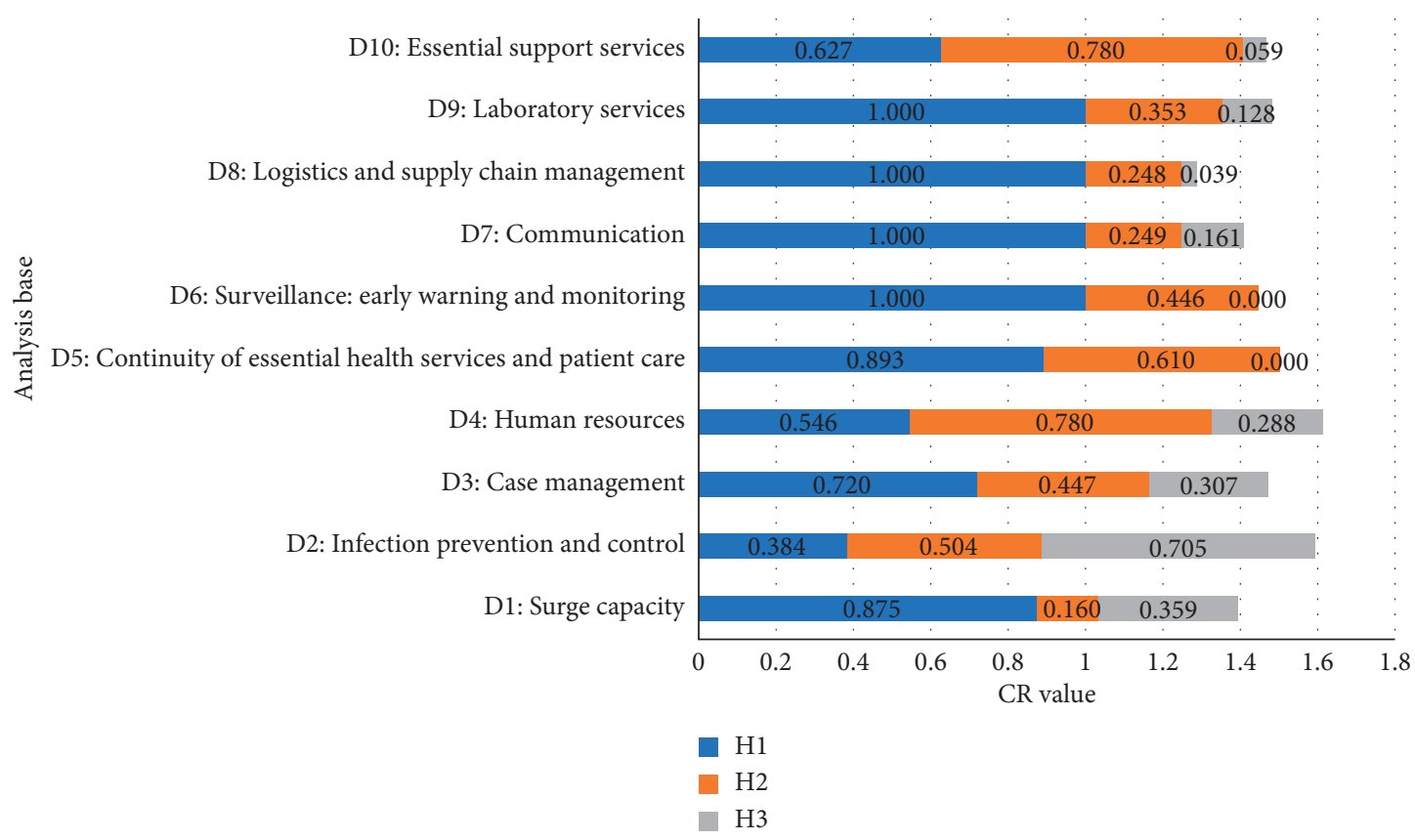

FIGURE 7: Obtained CR values of hospitals in terms of ten main components.

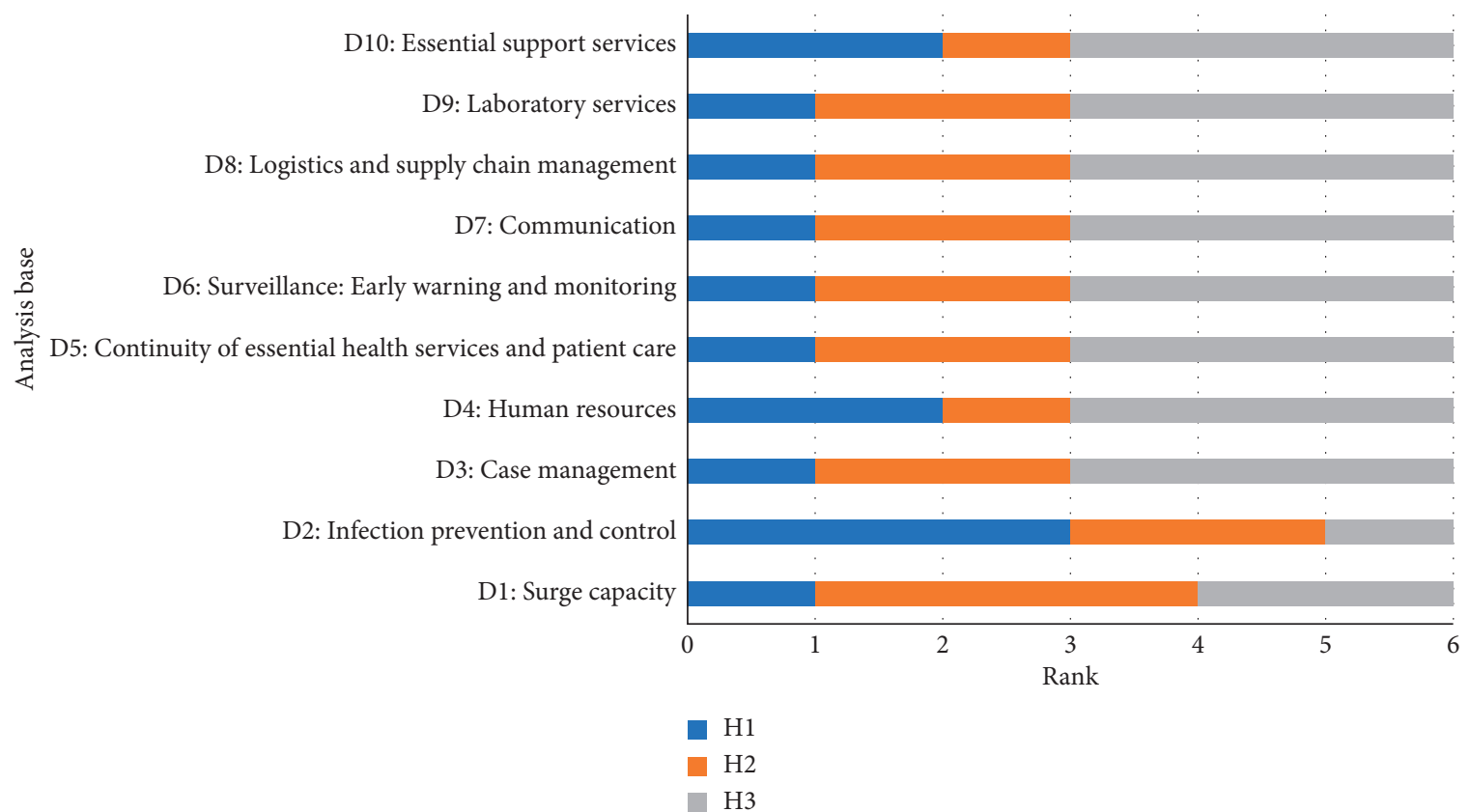

FIGURE 8: Ranking orders of hospitals in terms of ten main components.

TABLE 3: Results of comparative study.

\begin{tabular}{|c|c|c|c|c|c|}
\hline \multirow{2}{*}{ Analysis base } & \multirow{2}{*}{ Hospital } & \multicolumn{2}{|c|}{ The current study (IVSF-TOPSIS) } & \multicolumn{2}{|c|}{ Traditional F-TOPSIS [54] } \\
\hline & & IVSF-TOPSIS CR & Rank & F-TOPSIS CR & Rank \\
\hline \multirow{3}{*}{ D1 } & $\mathrm{H} 1$ & 0.875 & 1 & 0.426 & 1 \\
\hline & $\mathrm{H} 2$ & 0.160 & 3 & 0.382 & 3 \\
\hline & $\mathrm{H} 3$ & 0.359 & 2 & 0.400 & 2 \\
\hline \multirow{3}{*}{ D2 } & $\mathrm{H} 1$ & 0.384 & 3 & 0.651 & 3 \\
\hline & $\mathrm{H} 2$ & 0.504 & 2 & 0.672 & 2 \\
\hline & H3 & 0.705 & 1 & 0.713 & 1 \\
\hline
\end{tabular}


TABle 3: Continued.

\begin{tabular}{|c|c|c|c|c|c|}
\hline \multirow{2}{*}{ Analysis base } & \multirow{2}{*}{ Hospital } & \multicolumn{2}{|c|}{ The current study (IVSF-TOPSIS) } & \multicolumn{2}{|c|}{ Traditional F-TOPSIS [54] } \\
\hline & & IVSF-TOPSIS CR & Rank & F-TOPSIS CR & Rank \\
\hline \multirow{3}{*}{ D3 } & $\mathrm{H} 1$ & 0.720 & 1 & 0.689 & 1 \\
\hline & $\mathrm{H} 2$ & 0.447 & 2 & 0.650 & 2 \\
\hline & $\mathrm{H} 3$ & 0.307 & 3 & 0.642 & 3 \\
\hline \multirow{3}{*}{$\mathrm{D} 4$} & $\mathrm{H} 1$ & 0.546 & 2 & 0.478 & 2 \\
\hline & $\mathrm{H} 2$ & 0.780 & 1 & 0.540 & 1 \\
\hline & H3 & 0.288 & 3 & 0.424 & 3 \\
\hline \multirow{3}{*}{ D5 } & $\mathrm{H} 1$ & 0.893 & 1 & 0.578 & 1 \\
\hline & $\mathrm{H} 2$ & 0.610 & 2 & 0.526 & 2 \\
\hline & $\mathrm{H} 3$ & 0.000 & 3 & 0.383 & 3 \\
\hline \multirow{3}{*}{ D6 } & $\mathrm{H} 1$ & 1.000 & 1 & 0.615 & 1 \\
\hline & $\mathrm{H} 2$ & 0.446 & 2 & 0.527 & 2 \\
\hline & $\mathrm{H} 3$ & 0.000 & 3 & 0.465 & 3 \\
\hline \multirow{3}{*}{ D7 } & $\mathrm{H} 1$ & 1.000 & 1 & 0.665 & 1 \\
\hline & $\mathrm{H} 2$ & 0.249 & 2 & 0.396 & 2 \\
\hline & H3 & 0.161 & 3 & 0.335 & 3 \\
\hline \multirow{3}{*}{ D8 } & $\mathrm{H} 1$ & 1.000 & 1 & 0.695 & 1 \\
\hline & $\mathrm{H} 2$ & 0.248 & 2 & 0.500 & 2 \\
\hline & $\mathrm{H} 3$ & 0.039 & 3 & 0.404 & 3 \\
\hline \multirow{3}{*}{ D9 } & $\mathrm{H} 1$ & 1.000 & 1 & 0.808 & 1 \\
\hline & $\mathrm{H} 2$ & 0.353 & 2 & 0.646 & 2 \\
\hline & H3 & 0.128 & 3 & 0.554 & 3 \\
\hline \multirow{3}{*}{ D10 } & $\mathrm{H} 1$ & 0.627 & 2 & 0.374 & 1 \\
\hline & $\mathrm{H} 2$ & 0.780 & 1 & 0.364 & 2 \\
\hline & H3 & 0.059 & 3 & 0.230 & 3 \\
\hline
\end{tabular}

between the current study and the benchmark model, we can conclude that this proposed approach is appropriate and applicable for this area.

\section{Conclusion}

Fighting against the pandemic is carried out with the proper management of human resources, equipment, materials, and information. One of the essential parameters in combating pandemics is planning resources in environments where resources and time are limited. Hospital preparedness is a vital component of an emergency plan that can significantly reduce the impact of large-scale epidemics. Therefore, evaluating organizational readiness is an essential step in this planning process.

This study proposes a hospital preparedness assessment against the COVID-19 pandemic using the TOPSIS decisionmaking method alongside its IVSFS extension. The proposed approach is applied to rank three Turkish hospitals serving as tertiary healthcare services. The paper has adapted and used ninety-nine subcomponents under ten components in the model initially reported by the WHO in 2020. These components are concerned with the patient surge, infection monitoring and control, human resource, case management, communication, supply chain management, laboratory services, surveillance, and essential services. Under the weights of these subcomponents, a preparedness index for each hospital is obtained. The index is specifically computed individually for each hospital under each main dimension. This helps decision makers and policymakers observing the readiness level of the hospital from ten different viewpoints.
The results of the study indicate that $\mathrm{H} 1$ is the readiest hospital with the highest IVSF-TOPSIS CR value of 0.79 , considering all ten components. $\mathrm{H} 3$ is vice versa. It has the lowest CR value (0.24), which means that it is the least ready hospital among them. $\mathrm{H} 2$ is placed at the middle point with a $\mathrm{CR}$ value of 0.44 . Assuming that 0.5 is a threshold, we can say that only $\mathrm{H} 1$ is ready for the COVID-19 pandemic. Although the other two hospitals have acceptable CR values for the ten different analyses, they are not fully prepared. At this point, they should formulate a preparedness improvement plan considering their deficiencies and negative aspects.

Regarding the methodological side, the study follows a multicriteria decision-based approach since the nature of the problem fits well with this concept. Additionally, a relatively complex argument "IVSFSs" is merged with the TOPSIS multicriteria decision model. However, the approach benefits from the linguistic evaluation of hospital decision makers and does not require any precise hospital readiness assessment data in this regard. This is an essential advantage of the approach. It can be easily adapted to other hospitals. A national-scale assessment may be possible to improve mitigation ability against a pandemic. This assessment will be an essential guide for reducing the effects of outbreaks and improving personnel disaster preparedness training, organizing material management activities during the epidemic period, accelerating the response to outbreaks, and managing human resources appropriately.

\section{Data Availability}

No data were used to support this study. 


\section{Conflicts of Interest}

The authors declare that they have no conflicts of interest.

\section{References}

[1] R. M. Anderson, H. Heesterbeek, D. Klinkenberg, and T. D. Hollingsworth, "How will country-based mitigation measures influence the course of the COVID-19 epidemic?" The Lancet, vol. 395, no. 10228, pp. 931-934, 2020.

[2] World Health Organization, Coronavirus Disease 2019 (COVID-19) Situation Report-93, World Health Organization, Geneva, Switzerland, 2020, https://www.who.int/docs/ default-source/coronaviruse/situation-reports/20200422-sit rep-93-COVID-19.pdf? sfvrsn=35cf80d7_4.

[3] World Health Organization, Report of the WHO-China Joint Mission on Coronavirus Disease 2019 (COVID-19), World Health Organization, Geneva, Switzerland, 2020, https:// www.who.int/docs/default-source/coronaviruse/who-chinajoint-mission-on-COVID-19-final-report.pdf.

[4] Ministry of Health of the Republic of Turkey, COVID-19 Current Situation in Turkey, Ministry of Health of the Republic of Turkey, Ankara, Turkey, 2020, https://COVID19. saglik.gov.tr.

[5] World Health Organization, Hospital Readiness Checklist for COVID-19, World Health Organization, Geneva, Switzerland, 2020, http://www.euro.who.int/_data/assets/pdf_file/ 0010/430210/Hospital-Readiness-Checklist.pdf.

[6] M. Haghani, M. C. Bliemer, F. Goerlandt, and J. Li, "The scientific literature on Coronaviruses, COVID-19 and its associated safety-related research dimensions: a scientometric analysis and scoping review," Safety Science, vol. 129, Article ID 104806, 2020.

[7] D. R. Singer, "Health policy and technology challenges in responding to the COVID-19 pandemic," Health Policy and Technology, vol. 9, no. 2, pp. 123-125, 2020.

[8] K. Yoon and C. L. Hwang, "Methods for Multiple Attribute Decision Making w: Multiple Attribute Decision Making-Methods and Applications, a State-of-the-at Survey; Springer:"” pp. 128-140, Berlin, Germany, 1981.

[9] M. F. Ak and M. Gul, "AHP-TOPSIS integration extended with Pythagorean fuzzy sets for information security risk analysis," Complex \& Intelligent Systems, vol. 5, no. 2, pp. 113-126, 2019.

[10] V. Başhan, H. Demirel, and M. Gul, "An FMEA-based TOPSIS approach under single valued neutrosophic sets for maritime risk evaluation: the case of ship navigation safety," Soft Computing, vol. 24, pp. 18749-18764, 2020.

[11] H. Garg, Z. Ali, and T. Mahmood, “Algorithms for complex interval-valued q-rung orthopair fuzzy sets in decision making based on aggregation operators, AHP, and TOPSIS," Expert Systems, vol. 38, no. 1, Article ID e12609, 2020.

[12] H. Garg and R. Arora, "TOPSIS method based on correlation coefficient for solving decision-making problems with intuitionistic fuzzy soft set information," AIMS Mathematics, vol. 5, no. 4, p. 2944, 2020.

[13] H. Arora and K. Kumar, "A novel exponential distance and its based TOPSIS method for interval-valued intuitionistic fuzzy sets using connection number of SPA theory," Artificial Intelligence Review, vol. 53, no. 1, pp. 595-624, 2020.

[14] M. Yucesan and M. Gul, "Hospital service quality evaluation: an integrated model based on Pythagorean fuzzy AHP and fuzzy TOPSIS," Soft Computing, vol. 24, no. 5, pp. 3237-3255, 2020.
[15] M. Yucesan, S. Mete, F. Serin, E. Celik, and M. Gul, "An integrated best-worst and interval type-2 fuzzy TOPSIS methodology for green supplier selection," Mathematics, vol. 7, no. 2, p. 182, 2019.

[16] F. Kutlu Gündoğdu and C. Kahraman, "A novel fuzzy TOPSIS method using emerging interval-valued spherical fuzzy sets," Engineering Applications of Artificial Intelligence, vol. 85, pp. 307-323, 2019.

[17] A. Balin, "A novel fuzzy multi-criteria decision-making methodology based upon the spherical fuzzy sets with a real case study," Iranian Journal of Fuzzy Systems, vol. 17, no. 4, pp. 167-177, 2020.

[18] F. Kutlu Gündoğdu and C. Kahraman, "Spherical fuzzy sets and spherical fuzzy TOPSIS method," Journal of Intelligent \& Fuzzy Systems, vol. 36, no. 1, pp. 337-352, 2019.

[19] M. Nekoie-Moghadam, L. Kurland, M. Moosazadeh, P. L. Ingrassia, F. Della Corte, and A. Djalali, "Tools and checklists used for the evaluation of hospital disaster preparedness: a systematic review," Disaster Medicine and Public Health Preparedness, vol. 10, no. 5, pp. 781-788, 2016.

[20] S. Fallah-Aliabadi, A. Ostadtaghizadeh, A. Ardalan, F. Fatemi, B. Khazai, and M. R. Mirjalili, "Towards developing a model for the evaluation of hospital disaster resilience: a systematic review," BMC Health Services Research, vol. 20, no. 1, p. 64, 2020.

[21] M. L. Verheul and M. L. Dückers, "Defining and operationalizing disaster preparedness in hospitals: a systematic literature review," Prehospital and Disaster Medicine, vol. 35, no. 1, pp. 61-68, 2020.

[22] C. Der-Martirosian, T. A. Radcliff, A. R. Gable et al., "Assessing hospital disaster readiness over time at the US Department of Veterans Affairs," Prehospital and Disaster Medicine, vol. 32, no. 1, pp. 46-57, 2017.

[23] A. H. Kaji and R. J. Lewis, "Hospital disaster preparedness in los angeles county," Academic Emergency Medicine, vol. 13, no. 11, pp. 1198-1203, 2006.

[24] D. E. Marcozzi, R. Pietrobon, J. V. Lawler et al., “Development of a hospital medical surge preparedness index using a national hospital survey," Health Services and Outcomes Research Methodology, vol. 20, no. 1, pp. 60-83, 2020.

[25] F. Mulyasari, S. Inoue, S. Prashar et al., "Disaster preparedness: looking through the lens of hospitals in Japan," International Journal of Disaster Risk Science, vol. 4, no. 2, pp. 89-100, 2013.

[26] R. Y. Sunindijo, F. Lestari, and O. Wijaya, "Hospital safety index: assessing the readiness and resiliency of hospitals in Indonesia," Facilities, vol. 38, no. 1-2, pp. 39-51, 2019.

[27] M. Top, Ö. Gider, and Y. Tas, "An investigation of hospital disaster preparedness in Turkey," Journal of Homeland Security and Emergency Management, vol. 7, no. 1, 2010.

[28] S. M. Hosseini, M. Bahadori, M. Raadabadi, and R. Ravangard, "Ranking hospitals based on the disasters preparedness using the TOPSIS technique in western Iran," Hospital Topics, vol. 97, no. 1, pp. 23-31, 2019.

[29] M. A. Ortiz-Barrios, B. A. Aleman-Romero, J. RebolledoRudas et al., "The analytic decision-making preference model to evaluate the disaster readiness in emergency departments: the ADT model," Journal of Multi-Criteria Decision Analysis, vol. 24, no. 5-6, pp. 204-226, 2017.

[30] F. Rezaei and Z. Mohebbi-Dehnavi, "Evaluation of the readiness of hospitals affiliated to Isfahan University of Medical Sciences in unexpected events in 2017," Journal of Education and Health Promotion, vol. 8, no. 14, pp. 1-7, 2019. 
[31] M. Saeid, H. Khankeh, A. Habibisoola, M. Mohammadali, G. Hamidkolg, and B. Dadkhah, "Investigating hospital preparedness in Ardabil Province against unexpected accidents," Health in Emergencies and Disasters, vol. 4, no. 3, pp. 127-134, 2019.

[32] A. Alruwaili, S. Islam, and K. Usher, "Disaster preparedness in hospitals in the Middle East: an integrative literature review," Disaster Medicine and Public Health Preparedness, vol. 13, no. 4, pp. 806-816, 2019.

[33] S. A. N. Tabatabaei and S. Abbasi, "Risk assessment in social security hospitals of Isfahan Province in case of disasters based on the hospital safety index," International Journal of Health System and Disaster Management, vol. 4, no. 3, p. 82, 2016.

[34] W. N. Naser, P. L. Ingrassia, S. Aladhrae, and W. A. Abdulraheem, "A study of hospital disaster preparedness in South Yemen," Prehospital and Disaster Medicine, vol. 33, no. 2, pp. 133-138, 2018.

[35] N. M. Samsuddin, R. Takim, A. H. Nawawi, and S. N. A. Syed Alwee, "Disaster preparedness attributes and hospitals resilience in Malaysia," Procedia Engineering, vol. 212, pp. 371378, 2018.

[36] M. A. Marzaleh, R. Rezaee, A. Rezaianzadeh, M. Rakhshan, G. Hadadi, and M. Peyravi, "Emergency department preparedness of hospitals for radiation, nuclear accidents, and nuclear terrorism: a qualitative study in Iran," Iranian Red Crescent Medical Journal, vol. 21, no. 5, 2019.

[37] H. Shabanikiya, M. Jafari, H. A. Gorgi, H. Seyedin, and A. Rahimi, "Developing a practical toolkit for evaluating hospital preparedness for surge capacity in disasters," International Journal of Disaster Risk Reduction, vol. 34, pp. 423-428, 2019.

[38] H. Garg, M. Munir, K. Ullah, T. Mahmood, and N. Jan, "Algorithm for T-spherical fuzzy multi-attribute decision making based on improved interactive aggregation operators," Symmetry, vol. 10, no. 12, p. 670, 2018.

[39] F. Perveen PA, J. J. Sunil, K. V. Babitha, and H. Garg, "Spherical fuzzy soft sets and its applications in decisionmaking problems," Journal of Intelligent \& Fuzzy Systems, vol. 37, no. 3, pp. 1-14, 2019.

[40] K. Ullah, H. Garg, T. Mahmood, N. Jan, and Z. Ali, "Correlation coefficients for T-spherical fuzzy sets and their applications in clustering and multi-attribute decision making," Soft Computing, vol. 24, no. 3, pp. 1647-1659, 2020.

[41] K. Ullah, T. Mahmood, and H. Garg, "Evaluation of the performance of search and rescue robots using T-spherical fuzzy hamacher aggregation operators," International Journal of Fuzzy Systems, vol. 22, no. 2, pp. 570-582, 2020.

[42] Z. Yang, X. Li, H. Garg, and M. Qi, "Decision support algorithm for selecting an antivirus mask over COVID-19 pandemic under spherical normal fuzzy environment," International Journal of Environmental Research and Public Health, vol. 17, no. 10, p. 3407, 2020.

[43] S. Zeng, H. Garg, M. Munir, T. Mahmood, and A. Hussain, "A multi-attribute decision making process with immediate probabilistic interactive averaging aggregation operators of T-spherical fuzzy sets and its application in the selection of solar cells," Energies, vol. 12, no. 23, p. 4436, 2019.

[44] E. Ozceylan, B. Ozkan, M. Kabak, and M. Dagdeviren, "July). A survey on spherical fuzzy sets and clustering the literature," in International Conference on Intelligent and Fuzzy Systems, pp. 87-97, Springer, Berlin, Germany, 2020.
[45] F. K. Gündoğdu and C. Kahraman, "A novel spherical fuzzy analytic hierarchy process and its renewable energy application," Soft Computing, vol. 24, no. 6, pp. 4607-4621, 2020.

[46] C. Kahraman, F. K. Gundogdu, S. C. Onar, and B. Oztaysi, "Hospital location selection using spherical fuzzy TOPSIS," in Proceedings of the 2019 Conference of the International Fuzzy Systems Association and the European Society for Fuzzy Logic and Technology (EUSFLAT 2019), Atlantis Press, Prague, Czech Republic, September 2019.

[47] F. K. Gündoğdu, C. Kahraman, and A. Karaşan, "Spherical fuzzy VIKOR method and its application to waste management," in International Conference on Intelligent and Fuzzy Systems, pp. 997-1005, Springer, Berlin, Germany, 2019.

[48] F. Kutlu Gündoğdu and C. Kahraman, "A novel VIKOR method using spherical fuzzy sets and its application to warehouse site selection," Journal of Intelligent \& Fuzzy Systems, vol. 37, no. 1, pp. 1197-1211, 2019.

[49] F. Kutlu Gundogdu and C. Kahraman, "Extension of WASPAS with spherical fuzzy sets," Informatica, vol. 30, no. 2, pp. 269-292, 2019.

[50] F. K. Gündoğdu and C. Kahraman, "A novel spherical fuzzy QFD method and its application to the linear delta robot technology development," Engineering Applications of Artificial Intelligence, vol. 87, Article ID 103348, 2020.

[51] F. Kutlu Gündoğdu, "A spherical fuzzy extension of MULTIMOORA method," Journal of Intelligent \& Fuzzy Systems, vol. 38, no. 2, pp. 1-16, 2020.

[52] A. Karaşan, E. Boltürk, and F. K. Gündoğdu, "Assessment of livability indices of suburban places of istanbul by using spherical fuzzy CODAS method," in Decision Making with Spherical Fuzzy Sets, pp. 277-293, Springer, Berlin, Germany, 2020.

[53] S. Gül, "Spherical fuzzy extension of DEMATEL (SFDEMATEL)," International Journal of Intelligent Systems, vol. 35, no. 9, pp. 1329-1353, 2020.

[54] C.-T. Chen, "Extensions of the TOPSIS for group decisionmaking under fuzzy environment," Fuzzy Sets and Systems, vol. 114, no. 1, pp. 1-9, 2000. 